\title{
A nanoporous surface is essential for glomerular podocyte differentiation in three-dimensional culture
}

\author{
Cristina Zennaro' \\ Maria Pia Rastaldi ${ }^{2}$ \\ Gerald James Bakeine ${ }^{3}$ \\ Riccarda Delfino' \\ Federica Tonon' \\ Rossella Farra ${ }^{4}$ \\ Gabriele Grassi ${ }^{1,5}$ \\ Mary Artero 6 \\ Massimo Tormen ${ }^{7}$ \\ Michele Carraro' \\ 'Department of Medical, Surgical \\ and Health Sciences, University of \\ Trieste, Trieste, ${ }^{2}$ Fondazione IRCCS \\ Ca' Granda Ospedale Maggiore \\ Policlinico, Milan, ${ }^{3}$ Department of \\ Radiology, San Martino University \\ Hospital, University of Genoa, Genoa, \\ ${ }^{4}$ Department of Engineering and \\ Architecture, University of Trieste, \\ ${ }^{5}$ Department of Life Sciences, \\ Cattinara University Hospital, \\ University of Trieste, ${ }^{6} \mathrm{Azienda}$ \\ Sanitaria Universitaria Integrata di \\ Trieste, Trieste, ${ }^{7}$ IOM-CNR Area \\ Science Park, Trieste, Italy
}

This article was published in the following Dove Press journal:

International Journal of Nanomedicine

30 September 2016

Number of times this article has been viewed
Abstract: Although it is well recognized that cell-matrix interactions are based on both molecular and geometrical characteristics, the relationship between specific cell types and the three-dimensional morphology of the surface to which they are attached is poorly understood. This is particularly true for glomerular podocytes - the gatekeepers of glomerular filtration which completely enwrap the glomerular basement membrane with their primary and secondary ramifications. Nanotechnologies produce biocompatible materials which offer the possibility to build substrates which differ only by topology in order to mimic the spatial organization of diverse basement membranes. With this in mind, we produced and utilized rough and porous surfaces obtained from silicon to analyze the behavior of two diverse ramified cells: glomerular podocytes and a neuronal cell line used as a control. Proper differentiation and development of ramifications of both cell types was largely influenced by topographical characteristics. Confirming previous data, the neuronal cell line acquired features of maturation on rough nanosurfaces. In contrast, podocytes developed and matured preferentially on nanoporous surfaces provided with grooves, as shown by the organization of the actin cytoskeleton stress fibers and the proper development of vinculin-positive focal adhesions. On the basis of these findings, we suggest that in vitro studies regarding podocyte attachment to the glomerular basement membrane should take into account the geometrical properties of the surface on which the tests are conducted because physiological cellular activity depends on the three-dimensional microenvironment.

Keywords: podocytes, neurons, nanotechnology, basement membrane, differentiation, adhesion

\section{Introduction}

Cell culture studies remain an invaluable tool for understanding cell properties and molecular mechanisms of cell damage. However, traditional two-dimensional (2D) cell cultures poorly replicate the complex in vivo cell-matrix interactions in different tissues. This is especially true for ramified cells because the formation of precise cell ramifications is essential to convey appropriate signals in specific tissue microenvironments. Therefore, three-dimensional (3D) cell cultures are becoming a gold standard for in vitro studies and have been recently facilitated by rapidly evolving nanotechnologies which create different 3D surfaces by modifying existing biocompatible materials, such as silicon. ${ }^{1,2}$ For instance, cultured neurons have been tested on different nanosurfaces by several investigators. ${ }^{3,4}$ Structured materials which facilitate dendrite development, adhesion, and signaling may promote better understanding of neuronal repair from pathological conditions and present novel therapeutic strategies. ${ }^{5,6}$
Correspondence: Cristina Zennaro Department of Medical, Surgical and Health Sciences, University of Trieste, Cattinara Hospital, Strada di Fiume 447, 34149 Trieste, Italy

Tel +39403996229

Email czennaro@units.it
International Journal of Nanomedicine 2016: I 4 4957-4973

(c) $\odot \circledast \circledast 2016$ lennaro et al. This work is published and licensed by Dove Medical Press Limited. The full terms of this license are avalable at https//www.dovepress.com/terms.php

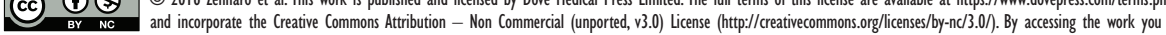
hereby accept the Terms. Non-conmercial uses of the work are permitted without any further permision from Dove Medical Press Limited, provided the work is properly attributed. For permission for commercial use of this work, please see paragraphs 4.2 and 5 of our Terms (https://www.dovepress.com/terms.php). 
Another example of the ramified cell is the glomerular podocyte. In contrast to neuronal dendrites, podocyte ramifications intertwine among themselves and organize a web that completely envelops the external side of the glomerular capillary, thus providing the morphological basis of glomerular filtration barrier function. Adhesion to the glomerular basement membrane (GBM) is a prerequisite of healthy podocytes; detachment from the GBM and loss of podocytes in the urine is a common finding in glomerular diseases. ${ }^{7-9}$ Despite a growing interest in potential therapeutic strategies to avoid podocyte detachment, there is incomplete knowledge of the dynamic mechanisms that regulate the anchorage of podocyte ramifications to the $\mathrm{GBM}^{7,8,10-12}$ in order to maintain physiological properties and counteract the continuous mechanical stress due to the high transcapillary filtration pressure. ${ }^{13}$

The use of biomaterials offers a unique method to produce surfaces with different nanotopographies and those best fitting cell-specific requirements. It is well known that cells sense, communicate, and respond to signals from biomaterials and exhibit different adhesion, proliferation, differentiation, and consequently gene expression depending on matrix morphology. ${ }^{2,5,14,15}$ The same occurs in vivo because the extracellular matrix (ECM) provides biophysical cues with its 3D morphology. ${ }^{16}$ These effects have been largely explored using neuronal cells in order to realize an optimal micro/nanometrical environment able not only to guide mature neuronal growth ${ }^{17}$ and dendrite orientation ${ }^{18}$ but also to drive neuronal differentiation..$^{5,19,20}$ The effect of substrate topography has been investigated at the micrometrical and nanometrical scale. ${ }^{5,19,21-24}$ Lines $350 \mathrm{~nm}$ wide made of polydimethylsiloxane increased neuronal differentiation with respect to flat controls. ${ }^{5}$ Polyethersulfone fiber mesh, $700 \mathrm{~nm}$ in diameter, increased rat neuronal precursors differentiation. ${ }^{19}$ Most of these surfaces are characterized by the presence of nanopillars conferring a rough aspect.

Glomerular podocytes with their elongated primary and secondary projections firmly attach to the basement membrane of the capillary. Because of their extreme differentiation, these cells have been always difficult to produce and maintain in culture, and in vitro studies often rely on cells with a scarcely ramified morphology.

Based on these premises and on the report that nanotopographies based on silicon were effective in improving cell adhesion and differentiation of different cell types and particularly of ramified cells,${ }^{25}$ we decided to test this type of material on podocyte cell cultures.

In consideration of current knowledge regarding the surface of the GBM based on scanning electron microscopy
(SEM) studies, ${ }^{26}$ we designed studies to compare rough nanomaterials with those possessing grooves instead of pillars and therefore presenting a porous surface on cross section, in order to study the behavior of podocytes and identify the specific surface on which these cells better adhere and differentiate. Our results seem to demonstrate that podocytes actually recognize a specific geometric pattern which is different from the one optimal for neuronal cells, supporting the idea that precise $3 \mathrm{D}$ microarchitectures mimicking the in vivo microenvironment may provide better conditions for in vitro studies.

\section{Materials and methods Nanopatterned substrates}

Silicon substrates with surface containing randomly selfassembled tin nanoislands with median surface areas of 69 (substrate N) and $163 \mathrm{~nm}^{2}$ (substrate F) and etched silicon nanopillars of 775 (substrate NE) and $405 \mathrm{~nm}^{2}$ (substrate FE) were used in this study. The substrates were realized as previously reported. ${ }^{15}$ Briefly, a distribution of randomly self-assembled nanoislands was obtained by controlled deposition of tin on the polished side of silicon wafers by thermal evaporation using a vacuum metallic evaporator (Balzer Vacuum Chamber Evaporator; OC Oerlikon, Freinbach, Switzerland). For thicknesses approximately $<20 \mathrm{~nm}$, the deposited tin assembles spontaneously into nanoislands that grow and eventually merge into larger ones as the evaporation proceeds, according to the Ostwald ripening phenomenon. ${ }^{27}$ Exploiting the formed nanoislands as protective masks, the wafers underwent a process of reactive ion etching in an STS inductively coupled plasma etcher to transfer the pattern onto the silicon support. Mean nanofeature size and density were controlled by the thickness of deposited tin and the height of the etched pillars by the duration of inductively coupled plasma treatment. Residual tin after etching was removed by wet etching. Non-patterned silicon substrate was used as control.

\section{Characteristics of nanopatterned surfaces}

Representative SEM (Zeiss Supra 40 at $5 \mathrm{kV}$ ) images of the substrates utilized in this study characterizing their surface topography are shown in Figure 1. Mean feature size, size distribution, random pattern, and density were quantified by 2D SEM images using ImageJ software (http://imagej. en.softonic.com). The substrates were also characterized by atomic force microscopy (AFM; AFM NanoWizard II JPK). Computerized statistical analysis of surface roughness was carried out using the surface profile data extracted from the AFM images (Gwddyion software) and expressed as 
A

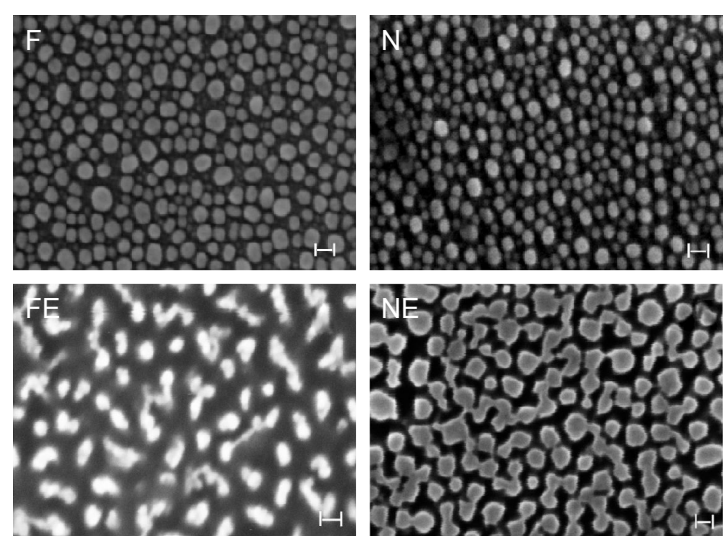

B

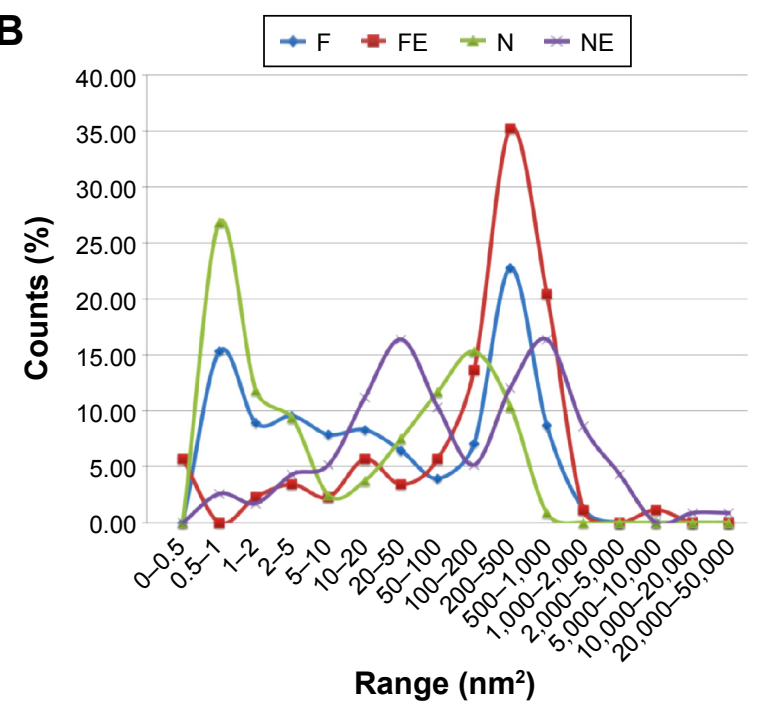

C
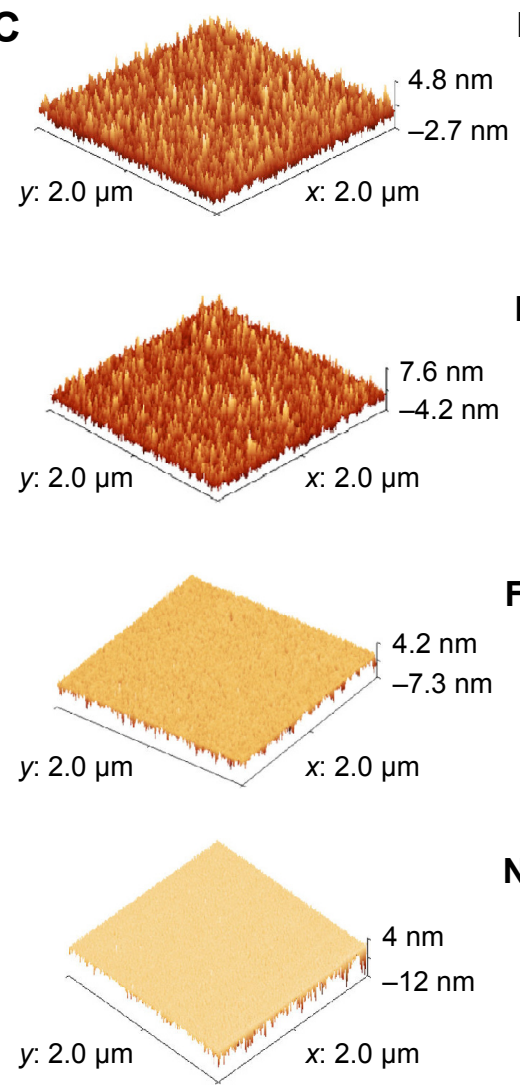

$\mathbf{F}$

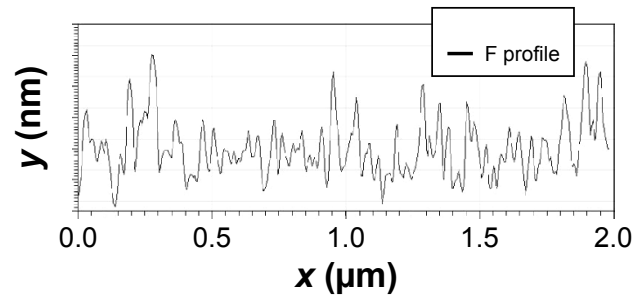

N

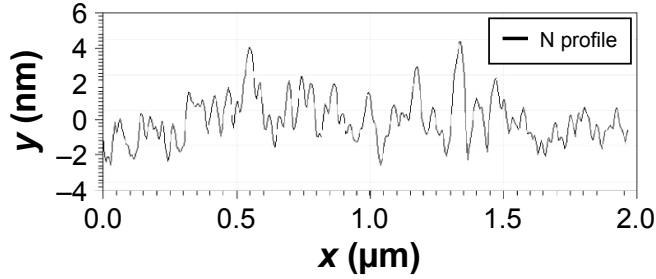

FE
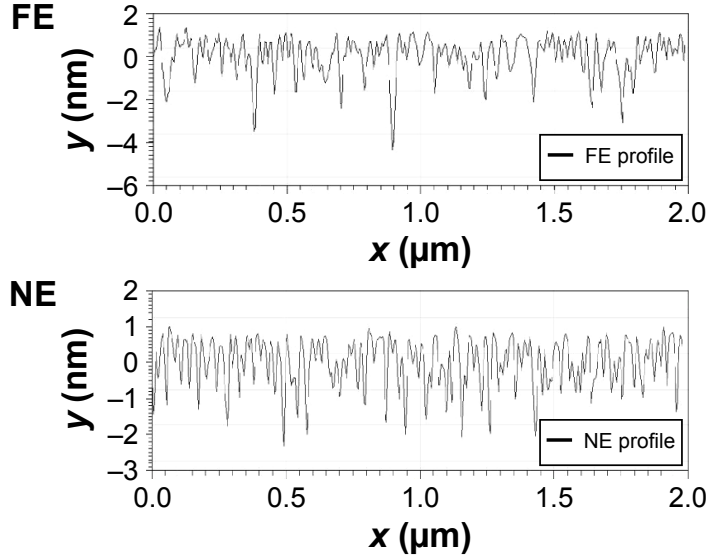

Figure I Features of nanosurfaces.

Notes: (A) SEM images clearly show the aspects of the different nanosurfaces utilized in the study. $\mathrm{F}$ and $\mathrm{N}$ surfaces are characterized by pillars, whereas FE and NE surfaces show grooves. Scale bars $=20 \mathrm{~nm}$. (B) Graph plot of the frequency distribution of surface area of substrate nanostructures sampled with 50 nm ${ }^{2}$ area classes. (C) AFM topography profiles.

Abbreviations: SEM, scanning electron microscopy; AFM, atomic force microscopy.

root mean square $(q)$. Table 1 illustrates the main surface parameters in terms of amplitude of pillars and grooves and their organization. Water contact angle measurements were obtained using a goniometer (CAM 100; KSV Instruments Ltd, Helsinki, Finland) equipped with a digital camera and image analysis software. Pure water was used as the wetting liquid.

All measurements were carried out in triplicate. Three random samples were observed each at three random spots for SEM, AFM, and water contact angle studies. 
Table I Characterization of nanostructured substrates used in this study

\begin{tabular}{|c|c|c|c|c|c|}
\hline \multirow[t]{2}{*}{ Substrate } & \multirow{2}{*}{$\begin{array}{l}\text { Average island/ } \\
\text { pillar size }\left(\mathrm{nm}^{2}\right)\end{array}$} & \multirow{2}{*}{$\begin{array}{l}\text { Surface area } \\
\text { coverage (\%) }\end{array}$} & \multirow{2}{*}{$\begin{array}{l}\text { Amplitude } \\
\text { Surface } \\
\text { roughness }(\mathrm{rms})\end{array}$} & \multicolumn{2}{|c|}{ Organization } \\
\hline & & & & $\begin{array}{l}\text { Surface } \\
\text { density (\%) }\end{array}$ & $\begin{array}{l}\text { Fractal } \\
\text { dimension }\end{array}$ \\
\hline $\mathrm{F}$ & 163 & 54 & $0.88 \mathrm{~nm}$ & 67.6 & 2.84 \\
\hline $\mathrm{FE}$ & 405 & 35 & $0.80 \mathrm{~nm}$ & 35.97 & 2.79 \\
\hline $\mathrm{N}$ & 69 & 38 & $1.20 \mathrm{~nm}$ & 33.67 & 2.79 \\
\hline NE & 775 & 53 & $0.63 \mathrm{~nm}$ & 63.7I & 2.89 \\
\hline
\end{tabular}

Abbreviation: rms, root mean square.

\section{Evaluation of protein adsorption on the different surfaces}

To quantify the amount of culture medium adsorbed onto the different surfaces, each surface was immersed in F12 Hank's medium/minimum essential medium (Sigma-Aldrich Co., St Louis, MO, USA) (1:1) supplemented with 15\% fetal bovine serum (FBS) or bovine serum albumin $(10 \mu \mathrm{g} / \mathrm{mL})$ or fibronectin $(5-20 \mu \mathrm{g} / \mathrm{mL})$ and incubated in a $37^{\circ} \mathrm{C}$ humidified $5 \% \mathrm{CO}_{2}$ atmosphere for 4 hours. Each surface was gently rinsed with phosphate-buffered saline at room temperature; adhering proteins were desorbed by soaking the surface in $1 \%$ sodium dodecyl sulfate for 15 minutes. Protein concentration in each eluate was determined using a commercially available kit (BCA assay kit; Pierce ${ }^{\mathrm{TM}}$; Thermo Fisher Scientific, Waltham, MA, USA). Experiments were run in triplicate.

\section{Cell cultures}

The protocols for isolation of rodent glomeruli and primary cells were approved by the Ethics Committee for Animal Experimentation (OPBA) of the University of Trieste (no PO1640ZEN1) in compliance with the Italian regulation (D.L.vo 26/2014) and the Directive 2010/63/EU of the European Parliament. The SHSY-5Y neuroblastoma cell line is a commercial line. The podocyte lines is diffusedly used in experimental studies and was kindly gifted by Dr G. Camussi (University of Torino). Ethical approval was not required by the EC/IRB of Italy because this study does not involve people, medical records, or human tissue. The human cellular lines are immortalized and do not require the authorization from Italian EC/IRB.

The silicon surfaces were subjected to conventional sterilization treatment by autoclaving prior to cell culture.

The SHSY-5Y human neuroblastoma cell line (IST Istituto Nazionale per la Ricerca sul Cancro, Genoa, Italy; no HTL95013) was cultured in a medium containing a 1:1 mixture of Eagle's minimum essential medium/F12 medium plus $15 \%$ FBS, $1 \%(\mathrm{v} / \mathrm{v})$ nonessential aminoacids, $1 \%$ $(\mathrm{v} / \mathrm{v})$ glutamine, and $1 \%(\mathrm{v} / \mathrm{v})$ penicillin/streptomycin (all from Euroclone S.p.A, Milan, Italy). For the differentiation experiments, the concentration of FBS was $10 \%$ in accordance with Constantinescu et al. ${ }^{28}$
For primary podocyte cultures, glomeruli from healthy 2-month-old male Sprague Dawley rats and C57BL6 mice were isolated by sieving, seeded in culture flasks precoated with collagen type IV, and covered by Dulbecco's Modified Eagle's Medium/F12 medium (DMEM/F12) supplemented with $10 \% \mathrm{FBS}, 5 \mu \mathrm{g} / \mathrm{mL}$ transferrin, $10^{-7} \mathrm{M}$ hydrocortisone, $5 \mathrm{ng} / \mathrm{mL}$ sodium selenite, $0.12 \mathrm{U} / \mathrm{mL}$ insulin, $100 \mu \mathrm{g} / \mathrm{mL}$ penicillin, $100 \mu \mathrm{g} / \mathrm{mL}$ streptomycin, and $2 \mathrm{mM}$ L-glutamine (all from Sigma-Aldrich Co.). After 10 days, first-passage podocytes were separated from glomeruli by an additional sieving through a $40 \mu \mathrm{m}$ mesh (BD Falcon; BD Biosciences; Discovery Labware, Bedford, MA, USA) and seeded onto the nanosurfaces or on plastic. Cell characterization was performed by immunofluorescence and real-time polymerase chain reaction for the podocyte markers nephrin, podocin, and WT-1 (Santa Cruz Biotechnology Inc., Dallas, TX, USA).

A human immortalized podocyte cell line was obtained by infection of primary cultures with a hybrid Adeno5/SV40 virus as previously described and characterized ${ }^{29}$ and cultured in DMEM containing $25 \mathrm{mM}$ glucose, $10 \%$ inactivated FBS, $100 \mathrm{U} / \mathrm{mL}$ penicillin, and $100 \mu \mathrm{g} / \mathrm{mL}$ streptomycin at $37^{\circ} \mathrm{C}$. All cell types were seeded on the nanosurfaces or on plastic coverslips at a density of $8 \times 10^{3}$ cells $/ \mathrm{cm}^{2}$.

\section{Evaluation of nanosurface biocompatibility}

The biocompatibility of the different surfaces was assessed from 1 to 5 days of culture on SHSY-5Y cells by quantifying cell toxicity and metabolic activity. The degree of cell toxicity was correlated to the production of lactate dehydrogenase measured by an assay kit (Biovision Research Product, Mountain View, CA, USA) according to the manufacturer's instructions; $1 \%$ Triton X-100-damaged cells were utilized as positive control. Metabolic activity was determined by the MTT (3-(4,5-dimethylthiazol-2-yl)-2,5-diphenyltetrazolium bromide) test (Sigma-Aldrich Co.), conducted according to the standard procedures. Cell differentiation was achieved by adding $10 \mu \mathrm{M}$ all-trans-retinoic acid (RA; Sigma-Aldrich Co.), as described. ${ }^{30,31}$ 


\section{Cell observation}

The physical characteristics of the silicon surfaces made it impossible to use standard microscopy to examine cellular morphology. To overcome this problem, we utilized Dil (1,1'-dioctadecyl-3,3,3',3'-tetramethylindocarbocyanine perchlorate) staining and SEM.

Dil (Molecular Probes ${ }^{\mathrm{TM}}$; Thermo Fisher Scientific), a lipophilic dye that becomes fluorescent when incorporated into the cell membrane, was added $(1 \mu \mathrm{g} / \mathrm{mL})$ to the medium 40 minutes before cell fixation; after extensive washing with phosphate buffer, cells were fixed in $4 \%$ paraformaldehyde.

For SEM examination, cells were fixed in $2.5 \%$ glutaraldehyde in $0.2 \mathrm{M}$ sodium cacodylate buffer at $\mathrm{pH} 7.4$ and post-fixed in $2 \% \mathrm{OsO}_{4}$ in $0.1 \mathrm{M}$ sodium cacodylate buffer at $\mathrm{pH} 7.4$, dehydrated in a graded ethanol series, and dried in hexamethyldisilazane. The samples were then sputter-coated with gold (Edwards S150A sputter coater) and observed under a XL30 Philips microscope. All reagents and grids for electron microscopy were from Electron Microscopy Sciences (Società Italiana Chimici, Rome, Italy).

\section{Analysis of cell proliferation and differentiation}

To measure the effect of different surfaces on cell differentiation, bromodeoxyuridine (BrdU; BD Biosciences, San Jose, CA, USA) incorporation and neurite length were analyzed at day 5 of neuronal cell culture. Cell count was performed by DAPI (4',6-diamidino-2-phenylindole) staining using ten fields at low $(\times 50)$ magnification, whereas circularity was analyzed with higher magnification images $(\times 400 ; 20$ fields). Circularity was calculated with ImageJ software, utilizing a macro that assigns the value of 1.0 to indicate a perfect circle and values progressively approaching 0.0 to indicate an increasingly elongated polygon.

Cell cycle phase evaluation and BrdU incorporation were performed as described, ${ }^{32}$ and cells were analyzed by flow cytometry (FACSCanto, BD Biosciences, San Jose, CA, USA; DIVA software, Dialogic, Quebec, MTL, Canada). Image J software was used to measure the length of individual neurites in ten images for each experiment at a magnification of $\times 100$; for this analysis, the cells were stained with Dil. All experiments were performed in triplicate.

\section{Gene expression study}

Total RNA was isolated from cells using the Invitrogen Pure Link ${ }^{\mathrm{TM}}$ Micro-to-Midi Total RNA Purification System (Thermo Fisher Scientific), and its concentration was determined by Nanoquant (Tecan Group Ldl, Mannedorf, Switzerland). One microgram of total RNA was reverse transcribed using MMLV reverse transcriptase (Thermo Fisher Scientific) and utilized for semiquantitative real-time polymerase chain reaction, as described. ${ }^{33}$

Human primers were the same as described by Constantinescu et al. ${ }^{28}$ Human GAPDH was utilized as house-keeping gene with the following primers: $5^{\prime}$-CCC ATCACCATCTTCCAGGAG-3' (forward) and 5'-CTTCT CCATGGTGGTGAAGACG-3' (reverse) (NM_002046.5).

Mouse primers were the following: MAP2 5'-AAGTCA CTGTGGAATAAGC-3' (forward) and 5'-CTCTGCGAAT TGGTTCTG-3' (reverse) (NM_001039934.1); $\beta$-tubulin III 5'-GCCTCCTCTCACAAGTATG-3' (forward) and 5'-CTCCGTATAGTGCCCTT-3' (reverse) (NM_023279.2); Tau 5'-CAAGACCAAGAAGGAGACATGGAC-3' (forward) and 5'-CACACGAGCTTGAGTCACATGC-3' (reverse) (M18776.1); and GAPDH 5'-AAATGGT GAAGGTCGGTGTG-3' (forward) and 5'-TGAAGGG GTCGTTGATGG-3' (reverse) (GU214026.1).

\section{Immunofluorescence staining}

An indirect immunofluorescence method was utilized on cells fixed in paraformaldehyde. The primary antibodies were rabbit anti-MAP2 (Merck Millipore, Billerica, MA, USA), rabbit anti-vinculin (Sigma-Aldrich Co.), and rabbit anti- $\beta$-tubulin III (Sigma-Aldrich Co.). Alexa Fluor 488 donkey anti-rabbit antibody was applied as secondary antibody (Invitrogen; Thermo Fisher Scientific), and DAPI was utilized as nuclear counterstain. F-actin was detected by phalloidin-FITC or phalloidin-rhodamine (SigmaAldrich Co.). Samples were observed under a fluorescence microscope (Leica Microsystems, Wetzlar, Germany). Nuclei were stained with DAPI (Sigma-Aldrich Co.).

\section{Data analysis}

All experiments were carried out in triplicate, and statistical analysis was performed using JMP 10 (Statistical Discovery Software from SAS Institute Inc., Cary, NC, USA) software. Data are shown as mean \pm standard error. Where indicated, differences among groups were evaluated by analysis of variance and judged as significant when $P$-value was $<0.05$.

\section{Results}

\section{Characteristics of nanopatterned surfaces}

As shown in Figure 1, two rough surfaces ( $\mathrm{F}$ and $\mathrm{N}$ ) and two porous surfaces (FE and NE) were utilized in this study. Representative images of these nanostructured surfaces and 
their characterization by SEM, AFM, and water contact angle are reported in Figure 1.

Table 1 illustrates the main parameters of all surfaces in terms of amplitude of pillars and grooves and their organization.

The water drop contact angle demonstrated lower values for the porous surfaces $\mathrm{FE}$ and $\mathrm{NE}$ as compared to the rough surfaces $\mathrm{F}$ and $\mathrm{N}$, indicating higher wettability of $\mathrm{FE}$ and $\mathrm{NE}$ substrates, similar to that of collagen (Figure 2A).

In addition, all nanosurfaces adsorbed significantly more medium components and more bovine serum albumin than plastic and unpatterned silicon (Figure 2B), though without significant differences among themselves. Instead, at the used dosages, we were not able to identify any adsorbed fibronectin on any surfaces.

\section{Evaluation of nanosurface biocompatibility}

Previous studies have shown that SHSY-5Y cells differentiate toward a neuronal cell phenotype after 5 days of incubation with RA. ${ }^{28}$ In the current study, the cell line grown on flat silicon (Si-Ctrl) and on nanopatterned surfaces demonstrated significantly lower lactate dehydrogenase production than cells grown on plastic (Figure 3A) and showed increased metabolic activity which, however, did not reach the level of cells grown on plastic and resembled more the level of those exposed to RA (Figure 3B).

\section{SHSY-5Y behavior on nanosurfaces}

$\beta$-Tubulin III immunostaining was used to analyze the cellular morphology on nontransparent surfaces as described by Qi et al. ${ }^{34}$ As expected, RA treatment caused elongation of the cell body and extension of multiple ramifications (Figure 4G). In the absence of RA, cells seeded on plastic (Figure 4A), on non-patterned silicon (Si-Ctrl) (Figure 4B), or on the porous materials FE (Figure 4C) and NE (Figure 4D) remained undifferentiated. In contrast, the presence of rough nanosurfaces ( $\mathrm{F}$ and $\mathrm{N}$ ) alone stimulated cell differentiation (Figure 4E and F), and cells seeded on the $\mathrm{N}$ rough material achieved ramification lengths comparable to that obtained
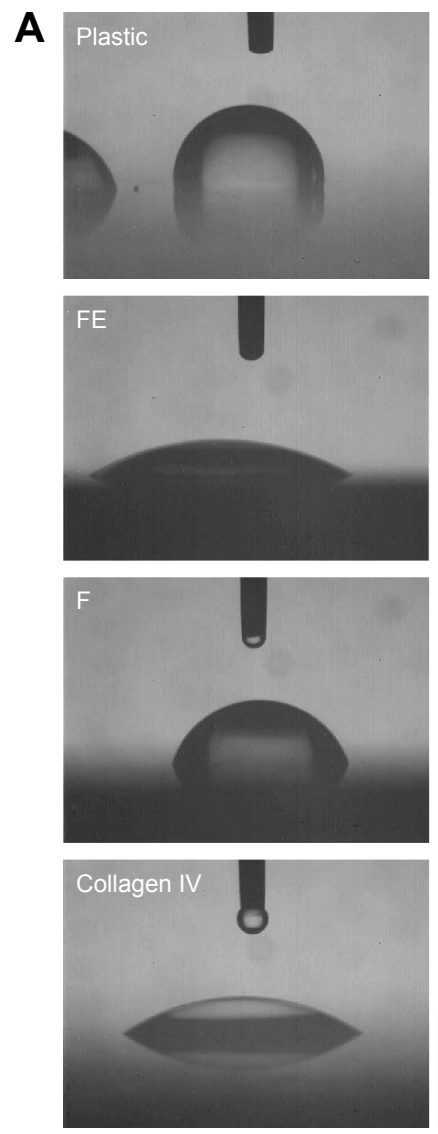
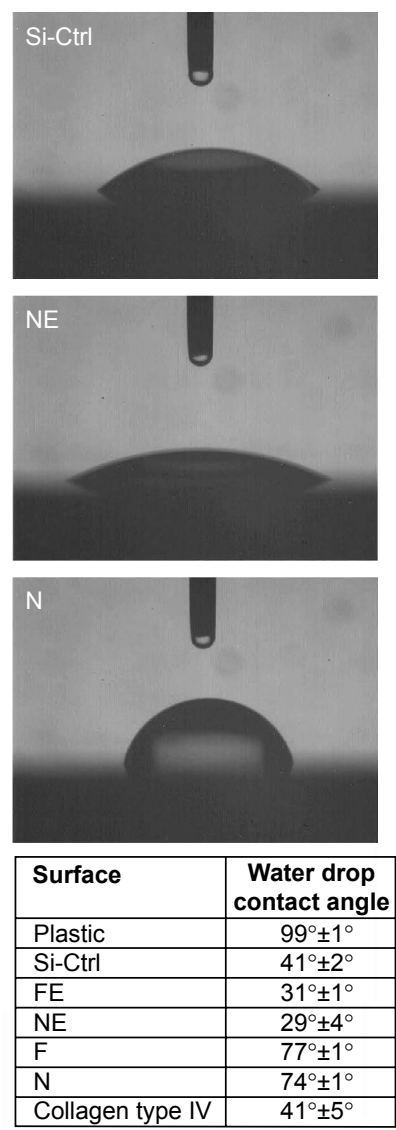
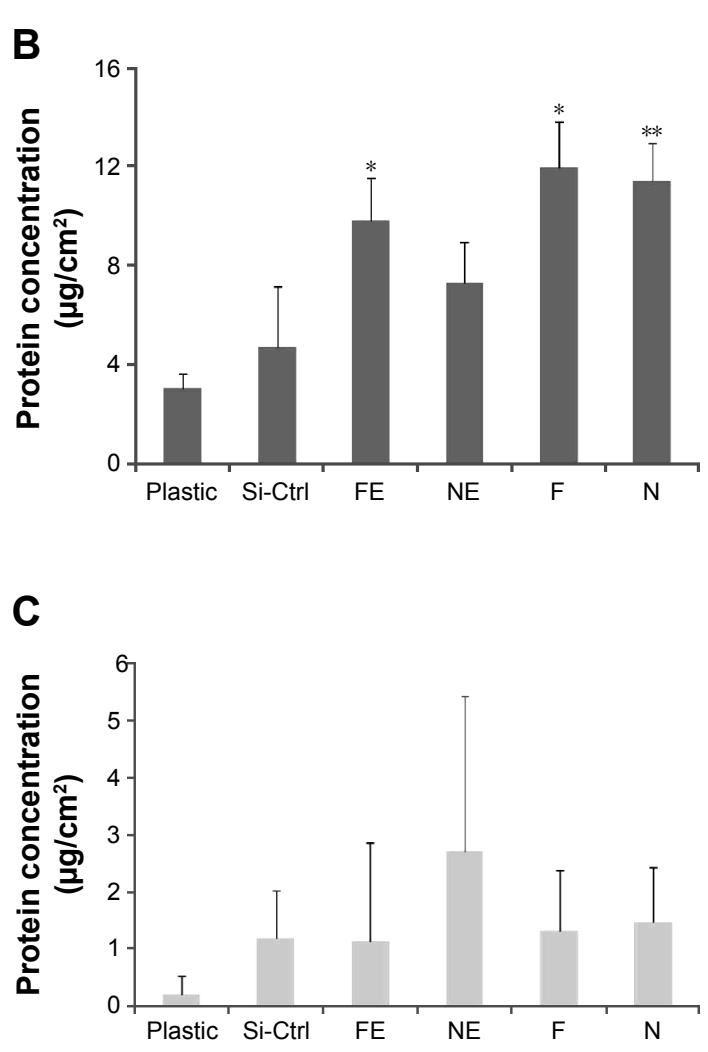

Figure 2 Water drop contact angle and protein absorption of nanosurfaces.

Notes: (A) Representative images of water drop contact angle of the surfaces included in this study. The table shows the measured values for each surface. After 4 hours of incubation, patterned surfaces show higher protein absorption from the whole medium (B) and higher BSA adsorption (C) than plastic and non-patterned silicon. The difference with plastic is statistically significant for $\mathrm{NE}, \mathrm{N}$, and $\mathrm{F}$ surfaces. ${ }^{*} \mathrm{P}<0.0 \mathrm{I} ; * * \mathrm{P}<0.00 \mathrm{I}$.

Abbreviations: BSA, bovine serum albumin; Si-Ctrl, unpatterned silicon surface. 

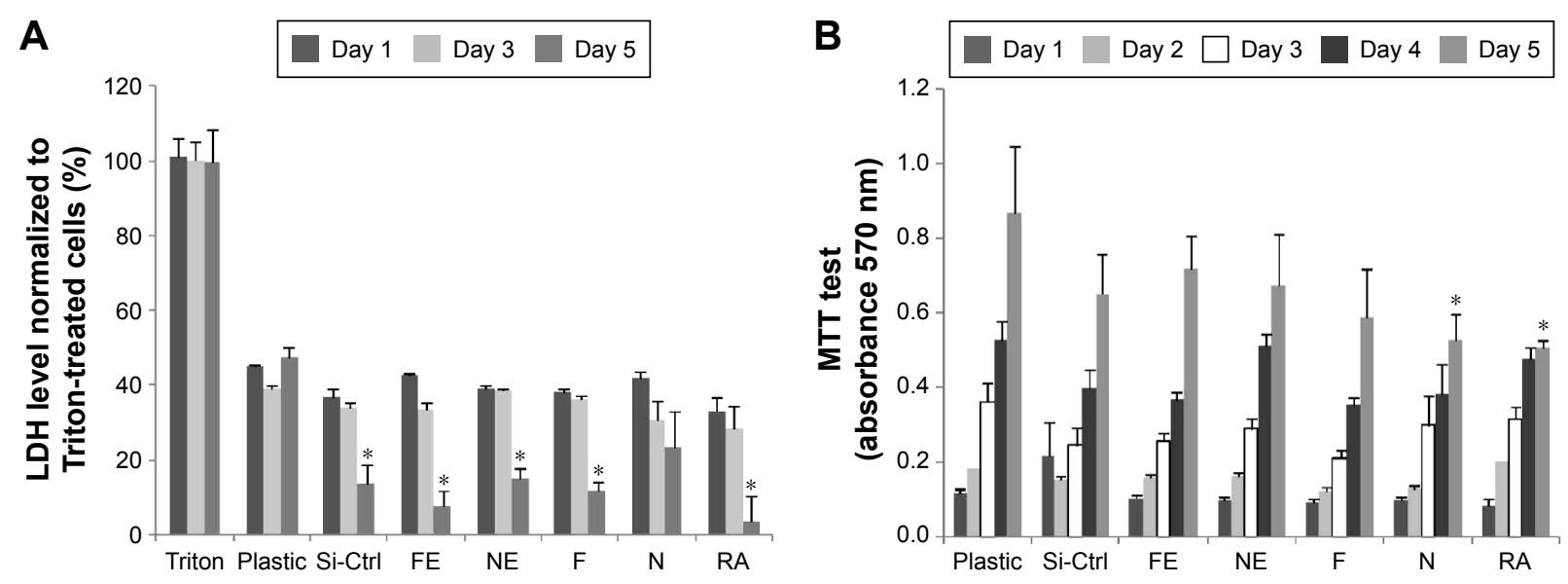

Figure 3 Nanosurface biocompatibility.

Notes: (A) LDH levels are compared to those produced after cell damage with Triton, taken as I00\%. SHSY-5Y cells after I (black bars) and 3 days (light gray bars) of culture display LDH levels reduced by $40 \%$ from baseline. At 5 days (gray bars), silicon surfaces and treatment with RA further diminish LDH release, which becomes statistically significant in comparison to the same time point on plastic. (B) MTT assay confirms that cells are healthy on all surfaces and at any time points. In addition, the test shows a statistically significant difference at 5 days between cells grown on plastic and those treated with RA or seeded on the $\mathrm{N}$ surface. Results are expressed as mean \pm SE. $* P<0.0$ l compared to plastic.

Abbreviations: LDH, lactate dehydrogenase; RA, retinoic acid; MTT, 3-(4,5-dimethylthiazol-2-yl)-2,5-diphenyl-tetrazolium bromide; SE, standard error; Si-Ctrl, unpatterned silicon surface.

by RA (Figure 4F). The parallel nuclear elongation on the $\mathrm{F}$ and $\mathrm{N}$ surfaces (Figure 4M, N, and P) associated with the cytoskeletal changes supports the presence of cell differentiation toward a neuronal phenotype that was comparable to RA treatment (Figure $4 \mathrm{O}$ and $\mathrm{P}$ ).

Neuronal differentiation induced by RA corresponds to a reduction of cell proliferation. ${ }^{30}$ Cell numbers comparable to RA treatment were obtained by growing cells onto the $\mathrm{N}$ surface (Figure 4Q). Although BrdU incorporation showed an insignificant reduction of cell proliferation (Figure 4K), cells seeded on the $\mathrm{N}$ rough material achieved ramification lengths comparable to that obtained by RA (Figure 4I).

\section{Expression studies on SHSY-5Y cells}

As shown by Constantinescu et al, ${ }^{28}$ once differentiated, SHSY-5Y cells express cytoskeletal and neurotransmitter markers typical of dopaminergic neurons. Accordingly, after 5 days of culture on rough nanosurfaces, MAP2 expression was higher compared to other culture conditions and similar to RA-treated cells (Figure 5A). Immunofluorescence showed appropriate protein localization on cell ramifications (Figure 5C). On the contrary, cells grown on porous surfaces expressed the molecule mainly in a perinuclear location.

Confirming previous data, ${ }^{28,35}$ neurotransmitter expression changes were not evident after 5 days of culture (Figure 5B) but required 10 days to become statistically significant (Figure 5D), particularly those of neurogenin and tyrosine hydroxylase which suggest a shift toward a dopaminergic phenotype. ${ }^{36}$ On the other hand, at the same time point, we no longer observed significant differences in expression of cytoskeletal molecules (Figure 5E), suggesting that modifications of the cytoskeleton are first required in order to achieve a complete differentiation.

Interestingly, all cells grown on nanopatterned materials showed a different gene expression as compared to cells seeded on plastic, suggesting recognition of and reactivity to uneven surfaces.

\section{Podocyte behavior on nanosurfaces}

In traditional 2D cell culture conditions, podocytes best develop when grown on collagen-coated plastic. This characteristic was confirmed in our experiments; Dil staining showed that podocytes remained undifferentiated and cuboid on uncoated plastic (Figure 6A2), whereas on collagencoated plastic, they acquired a differentiated, arborized phenotype (Figures 6G2 and 7E).

In contrast to SHSY-5Y cells, an undifferentiated podocyte pattern was observed on the rough nanosurfaces $\mathrm{F}$ and $\mathrm{N}$ (Figures 6C2 and D2 and 7A and B), whereas porous materials (FE and NE) induced a differentiated morphology characterized by elongation of the cell body and the appearance of an arborized phenotype (Figures 6E2, F2, and I and 7C and D). Evaluation of morphology by SEM (Figure 7F-J) and proliferation indexes (Figure $6 \mathrm{H}$ ) confirmed these observations. Accordingly, the presence of stress fibers typical of differentiated podocytes was observed in cells grown on porous surfaces (Figure 6E1 and F1) as well as on collagencoated plastic (Figure 6G1), whereas peripheral bundles of 

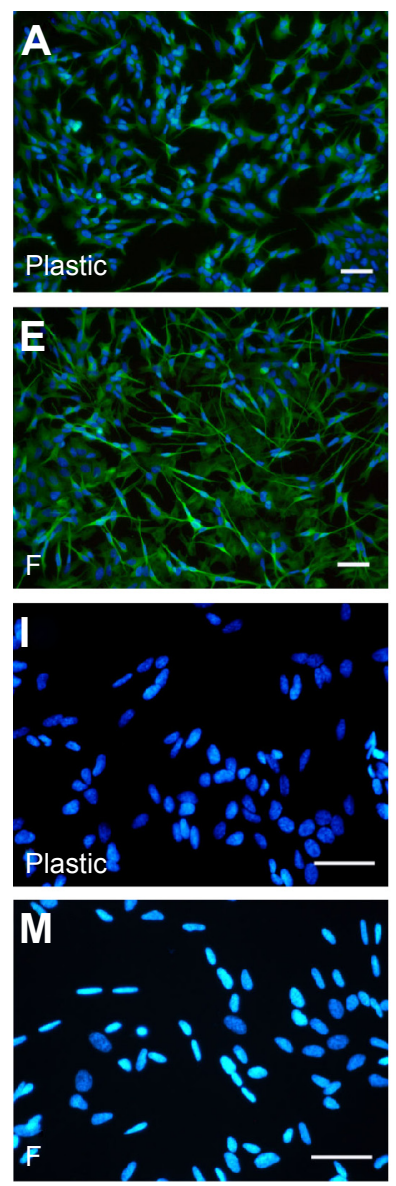

Q
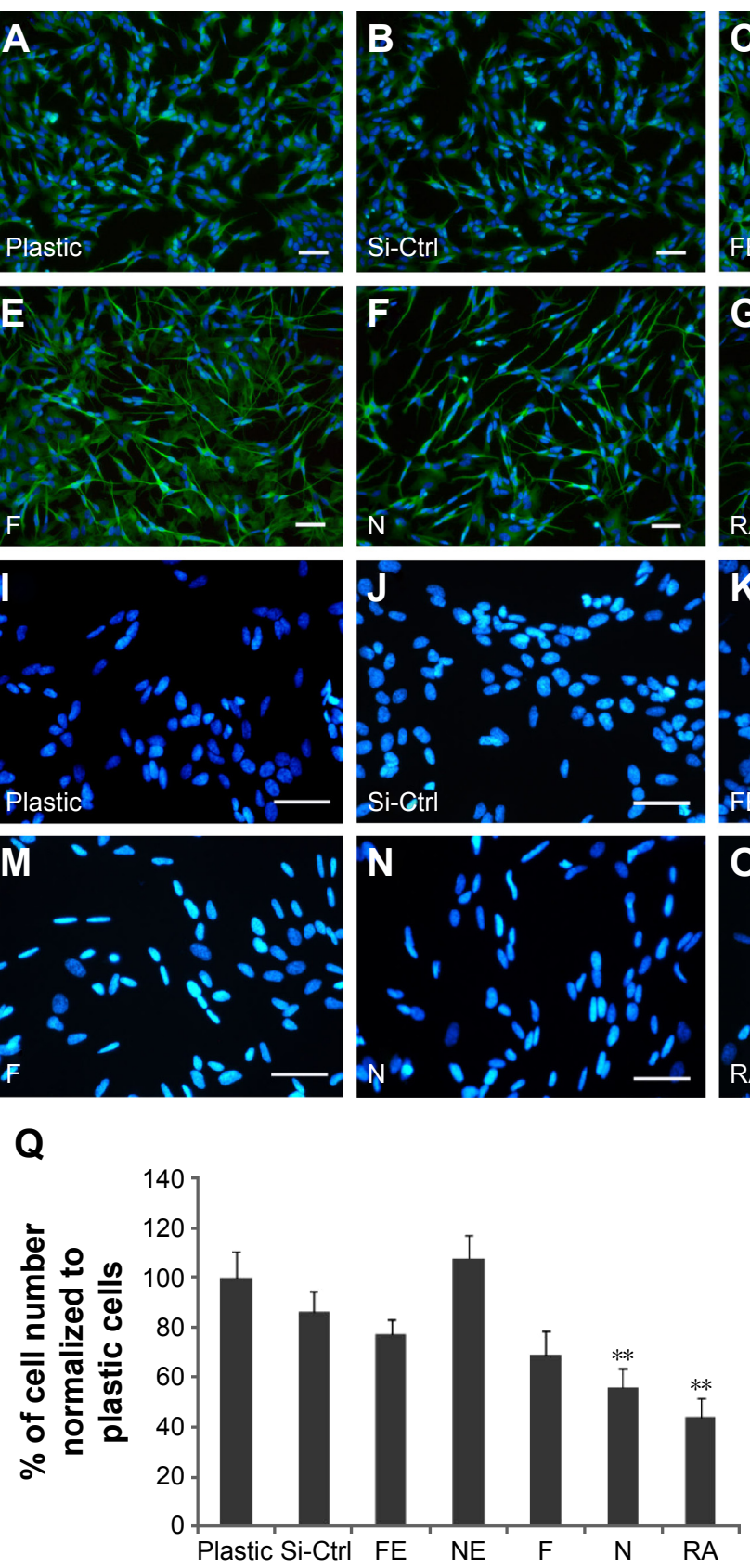
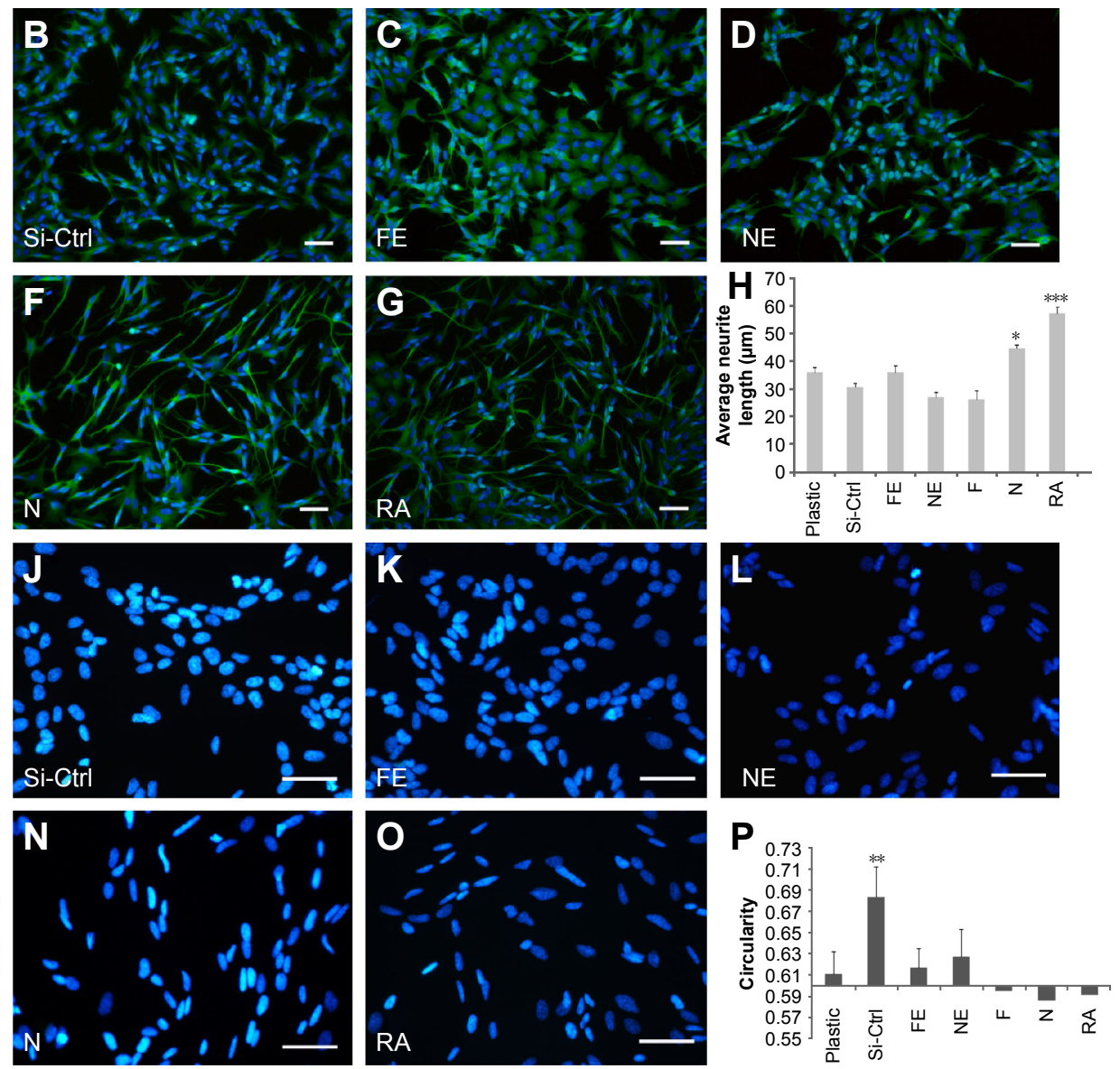

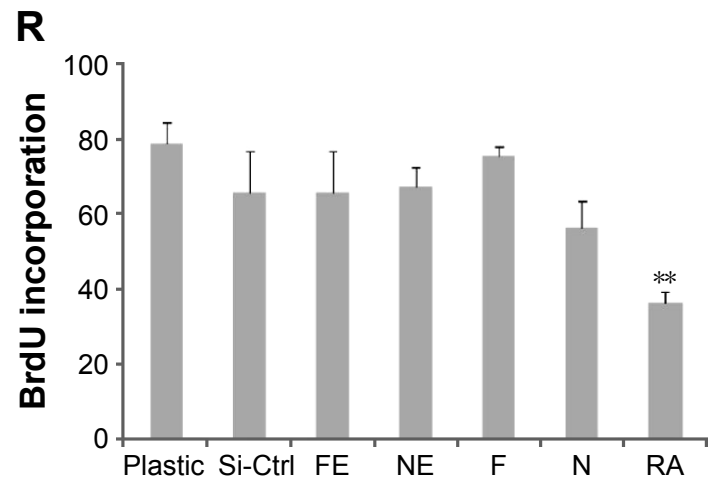

Figure 4 Behavior of SHSY-5Y cells on different nanosurfaces.

Notes: SHSY-5Y cells were immunostained with anti- $\beta$-tubulin III (green) and nuclei counterstained with DAPI (blue). The cells have an undifferentiated morphology, represented by short ramifications, when grown on (A) plastic, (B) non-patterned silicon, and porous materials (C) FE and (D) NE. A differentiated, elongated phenotype with long cell projections is present on rough materials $(\mathbf{E}) \mathrm{F}$ and $(\mathbf{F}) \mathrm{N}$, as well as after $(\mathbf{G})$ RA treatment. $(\mathbf{H})$ The graph shows the results of measurement of cell ramification length, which is significantly higher in cells grown on the surface $\mathrm{N}$ and after RA treatment. By evaluation at higher magnification, the nuclear shape appears mostly rounded in cells grown on (I) plastic, $(\mathbf{J})$ unpatterned silicon, or on the porous materials $(\mathbf{K})$ FE and $(\mathbf{L})$ NE, whereas adherence to the rough surfaces (M) F and ( $\mathbf{N}) \mathbf{N}$ as well as exposure to $(\mathbf{O})$ RA seems to induce nuclear elongation. $(\mathbf{P})$ The graph shows the results obtained by measurement of nuclear circularity, which is the highest in cells cultivated on unpatterned silicon and the lowest in cells grown on rough surfaces or exposed to RA. (Q) In the histogram, the cell number is expressed as percentage of values shown by cells grown on plastic, taken as $100 \%$. A statistically significant decrease is shown by cells grown on the rough surface $\mathrm{N}$, as well as after RA treatment. (R) After 5 days of culture, only cells treated with RA display a statistically significant lower BrdU incorporation than cells grown on plastic. Scale bars $=50 \mu \mathrm{m}$. $(\mathbf{H}, \mathbf{P}, \mathbf{Q}$, and $\mathbf{R})$ Results are expressed as mean $\pm S E$. $* P<0.01$, $* * P<0.001$, and $* * * P<0.0001$ compared to plastic.

Abbreviations: DAPI, 4',6-diamidino-2-phenylindole; RA, retinoic acid; SE, standard error; Si-Ctrl, unpatterned silicon surface; BrdU, bromodeoxyuridine.

subcortical actin predominated in cells adherent to rough surfaces or uncoated plastic (Figure 6C1, D1, and A1). The observed cytoskeletal changes also involved the formation of focal adhesions, as shown by vinculin abundance and localization that paralleled actin changes (Figure 8). Fortyeight hours were sufficient for human podocytes to show a peripheral punctated vinculin pattern co-localizing at the tip of stress fibers (Figure 8A). At the same time point, both stress 

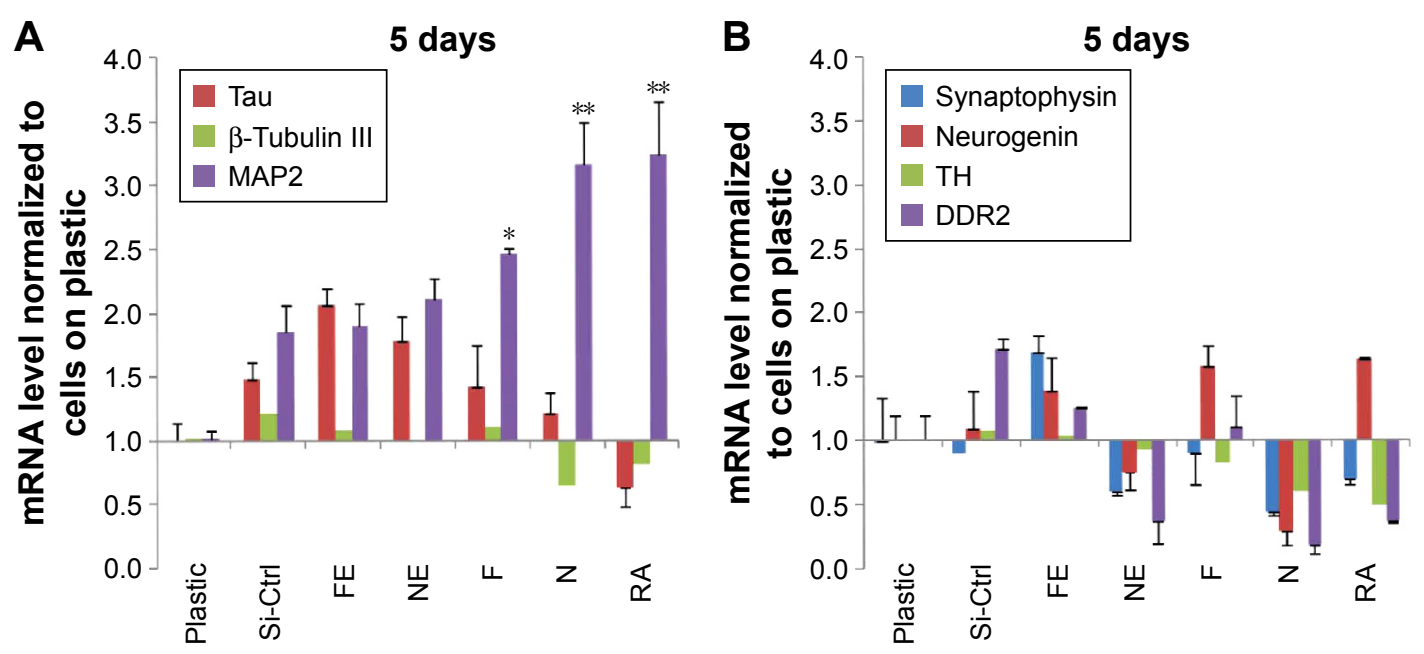

C
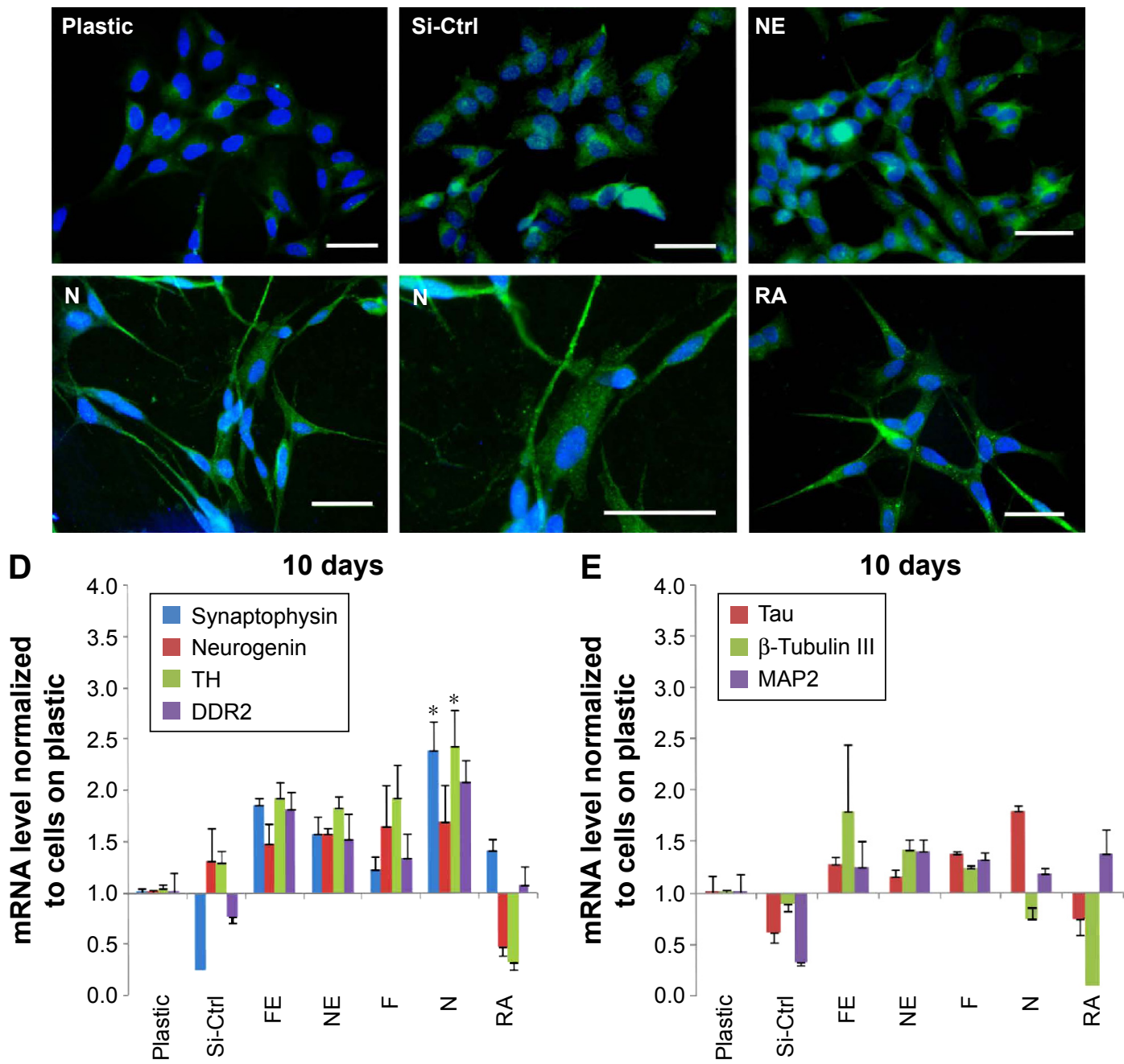

Figure 5 Expression studies on SHSY-5Y cells.

Notes: (A) Among the cytoskeletal components Tau (red bars), $\beta$-tubulin III (green bars), and MAP2 (violet bars), a significant increase of MAP2 expression is shown at 5 days of culture by cells grown on the rough surfaces $\mathrm{N}$ and $\mathrm{F}$, as well as by cells stimulated with RA. (B) The expression of molecules related to neurotransmission, including synaptophysin (blue bars), neurogenin (red bars), TH (green bars), and DDR2 (violet bars), is not significantly modified at 5 days of culture. (C) MAP2 staining on SHSY-5Y cells shows the molecule barely expressed by cells grown on plastic (first row, left panel), non-patterned silicon (Si-Ctrl, first row, middle panel), and the porous surface NE (first row, right panel). MAP2 expression along cell processes can be detected in cells grown on the surface N (second row, left panel), and better appreciated at higher magnification of the punctated square area (second row, middle panel), similar to what is observed in cells treated with RA (second row, right panel). Scale bars $=50 \mu \mathrm{m}$. (D) At 10 days, expression of synaptophysin (blue bars) and TH (green bars) is significantly increased in cells grown on the $\mathrm{N}$ surface, whereas at this time point, (E) the difference among cytoskeletal molecules is no longer present. $* P<0.01$ and $* * P<0.001$ compared to plastic.

Abbreviations: RA, retinoic acid; Si-Ctrl, unpatterned silicon surface. 

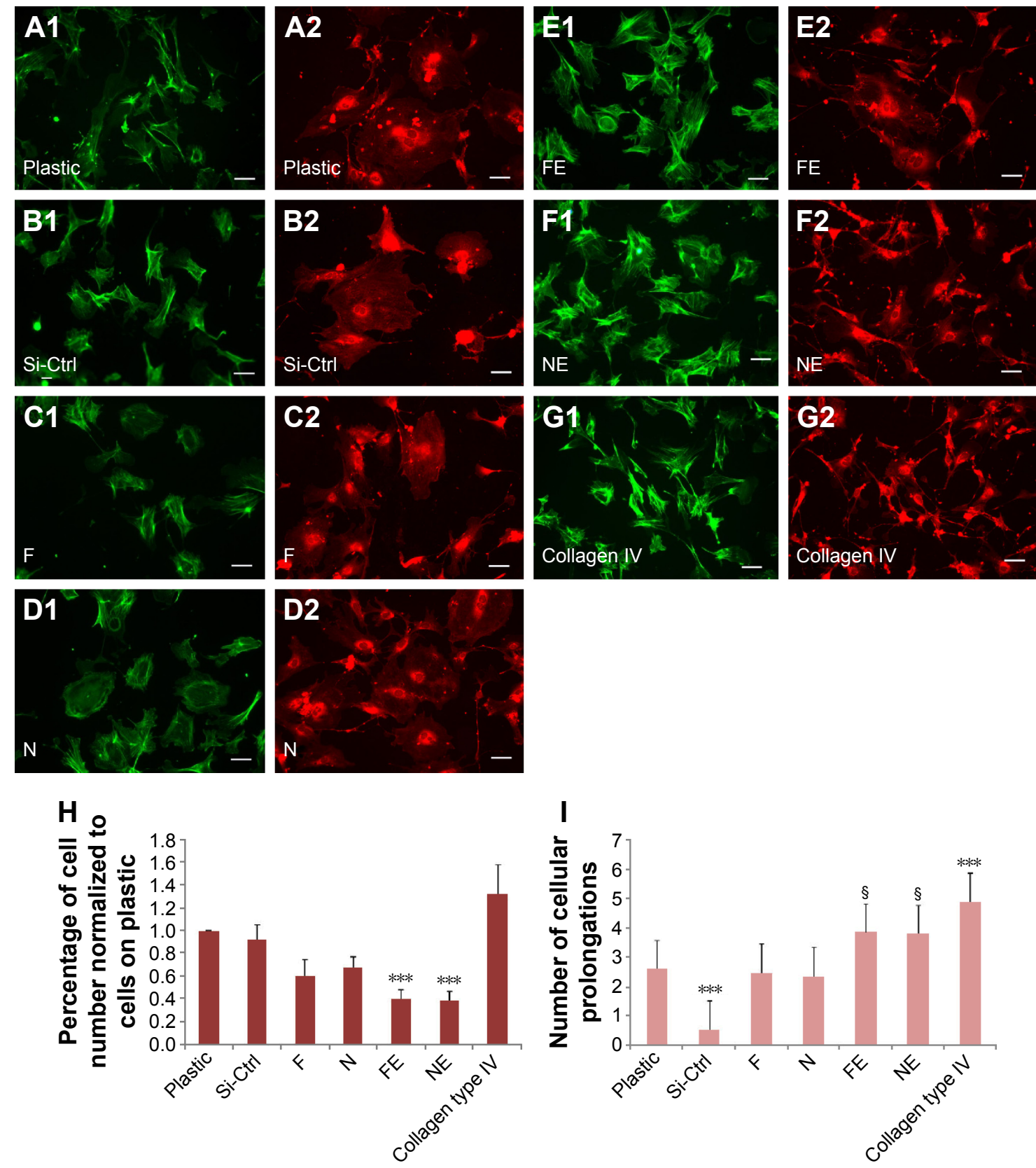

Figure 6 Morphology of primary mouse podocytes.

Notes: Representative F-actin (panels AI-GI) and Dil staining (panels A2-G2) images of primary mouse podocytes after 5 days of culture. Cobblestone phenotype and peripheral subcortical actin pattern are shown by cells grown on uncoated plastic (AI and $\mathbf{A 2}$ ), non-patterned silicon (BI and B2), and the rough surfaces $F(\mathbf{C I}$ and $\mathbf{C 2}$ ) and $\mathrm{N}$ (DI and D2). In contrast, cells seeded on the porous surfaces FE (EI and E2) and NE (FI and F2) resemble differentiated podocytes grown on collagen-coated plastic (G I and G2), showing elongated cell body, presence of numerous ramifications, and actin stress fibers. Scale bars $=50 \mu \mathrm{m}$. (H) The number of cells is significantly reduced as compared to uncoated plastic in presence of the FE and NE surfaces. (I) The cells on NE and FE surfaces show statistically significant increase of number of projections as compared to uncoated plastic. In contrast, exposure to unpatterned silicon greatly diminishes the number of cell processes. Results are expressed as mean $\pm S E$. $* * * P<0.000 \mathrm{I}$ and ${ }^{\S} P<0.05$. Abbreviations: Dil, I'-dioctadecyl-3,3,3',3'-tetramethylindocarbocyanine perchlorate; SE, standard error; Si-Ctrl, unpatterned silicon surface.

fibers and vinculin expression appeared decreased in the presence of rough materials (Figure $8 \mathrm{~B}$ ) but were increased in cells grown on porous nanosurfaces (Figure 7C).

At day 5 of culture on rough surfaces, vinculin expression was mostly cytoplasmic, and the pattern of expression suggested intramolecular head-to-tail binding typical of the inactive form of the molecule (Figure 9A). In contrast, porous materials influenced the punctated expression of active vinculin co-localizing with actin stress fibers at peripheral focal contacts (Figure 9B-D).

\section{Expression studies on podocytes}

Podocytes and neuronal cells share numerous lineagerestricted molecules, including cytoskeletal proteins such 

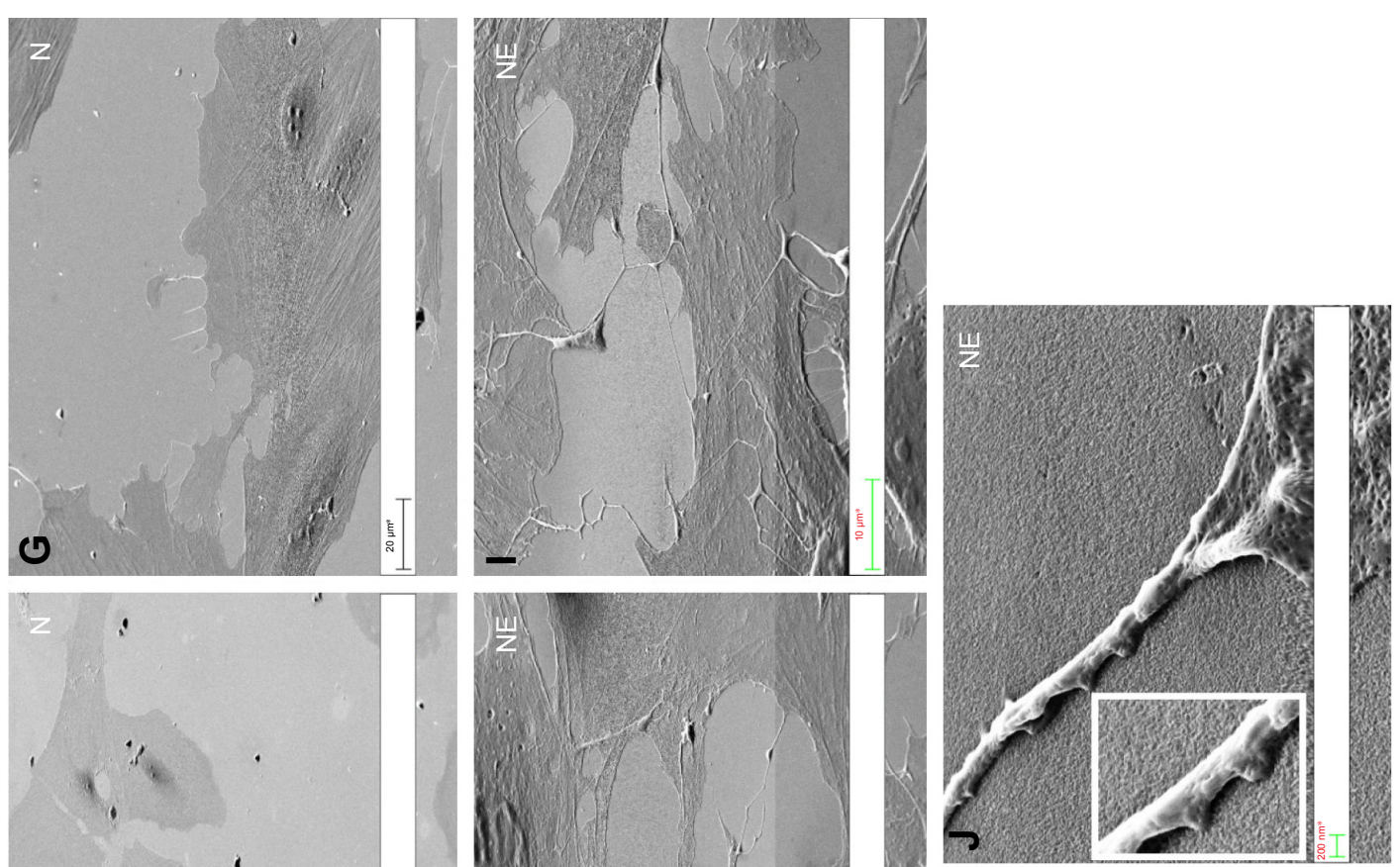

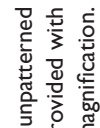

응

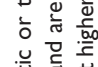

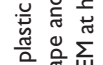

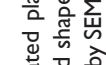

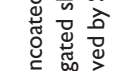

응

穿晏

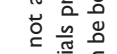

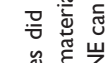
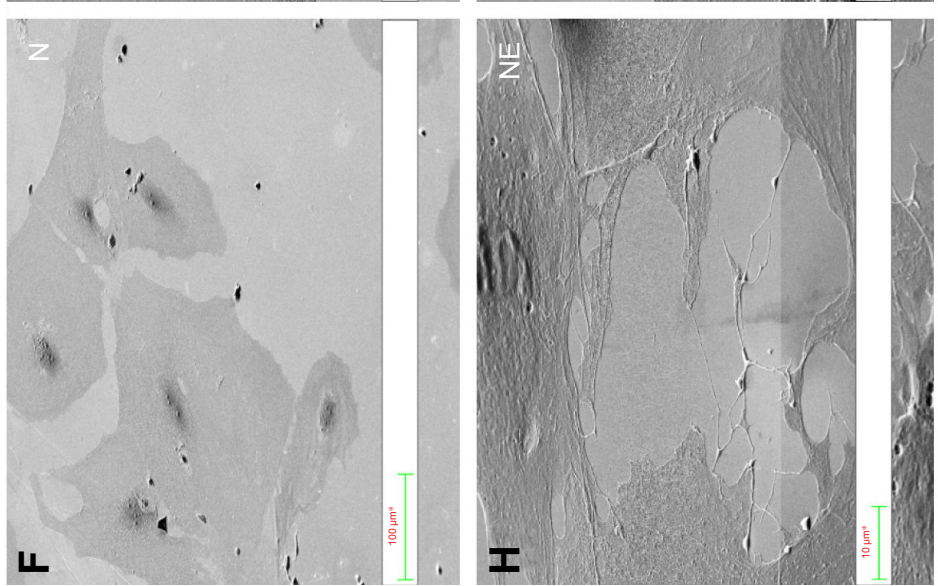

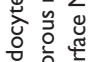

응흥

岁岂高

部

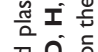

势

离崖亭

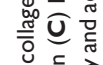

닫ำ

额

咅

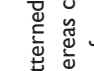

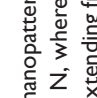

山
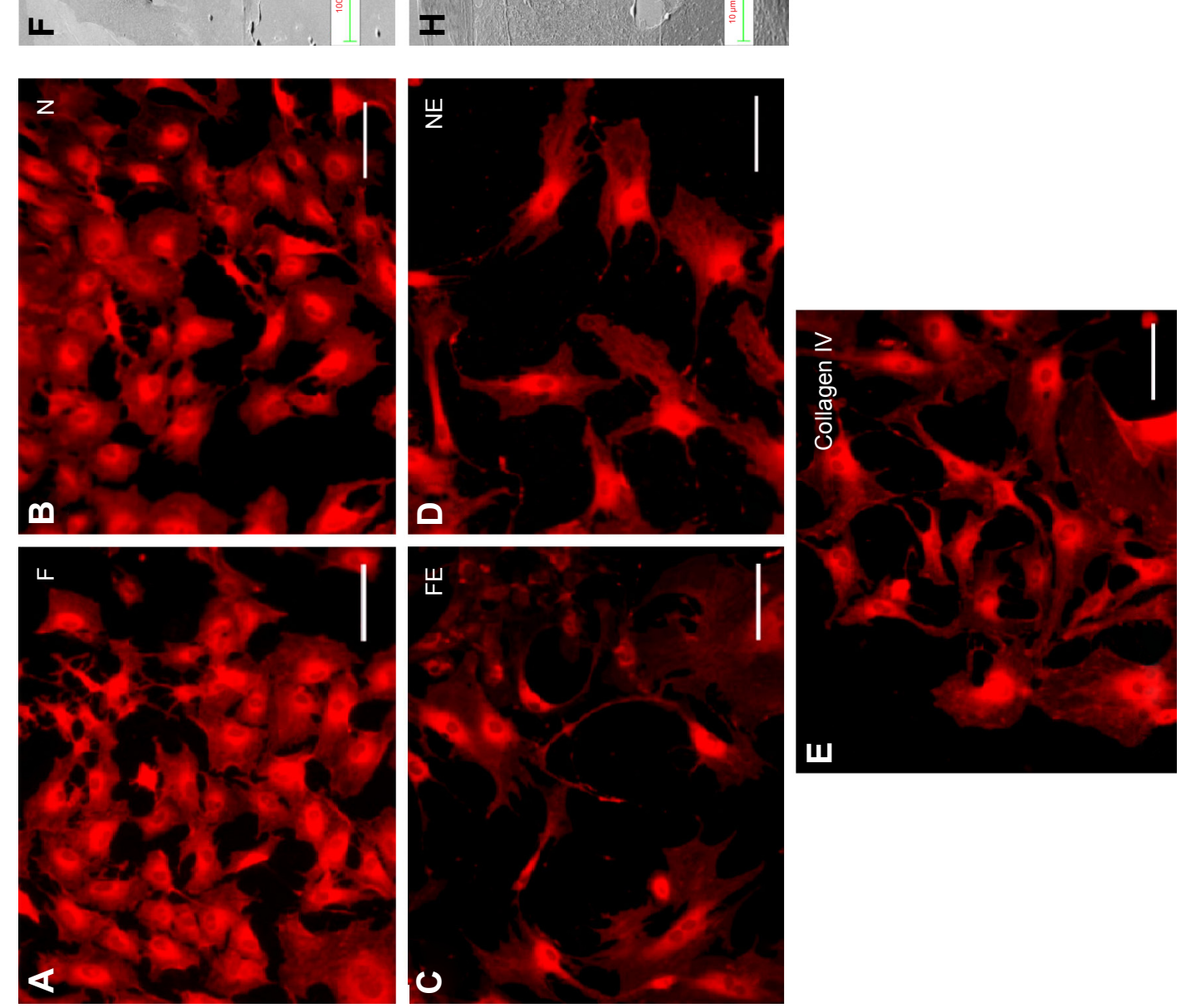

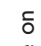

$$
\begin{aligned}
& \text { ○ } \\
& \text { 言岗包 }
\end{aligned}
$$$$
\text { पू है है }
$$$$
\text { 总造尊 }
$$

的起员

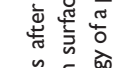

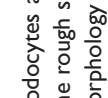

응 운

岩施

诺

政

है 造

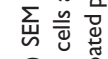

企市

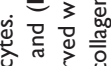

of no

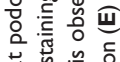

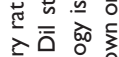

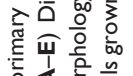

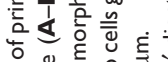

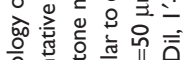

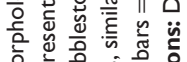

之o

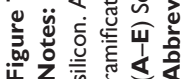



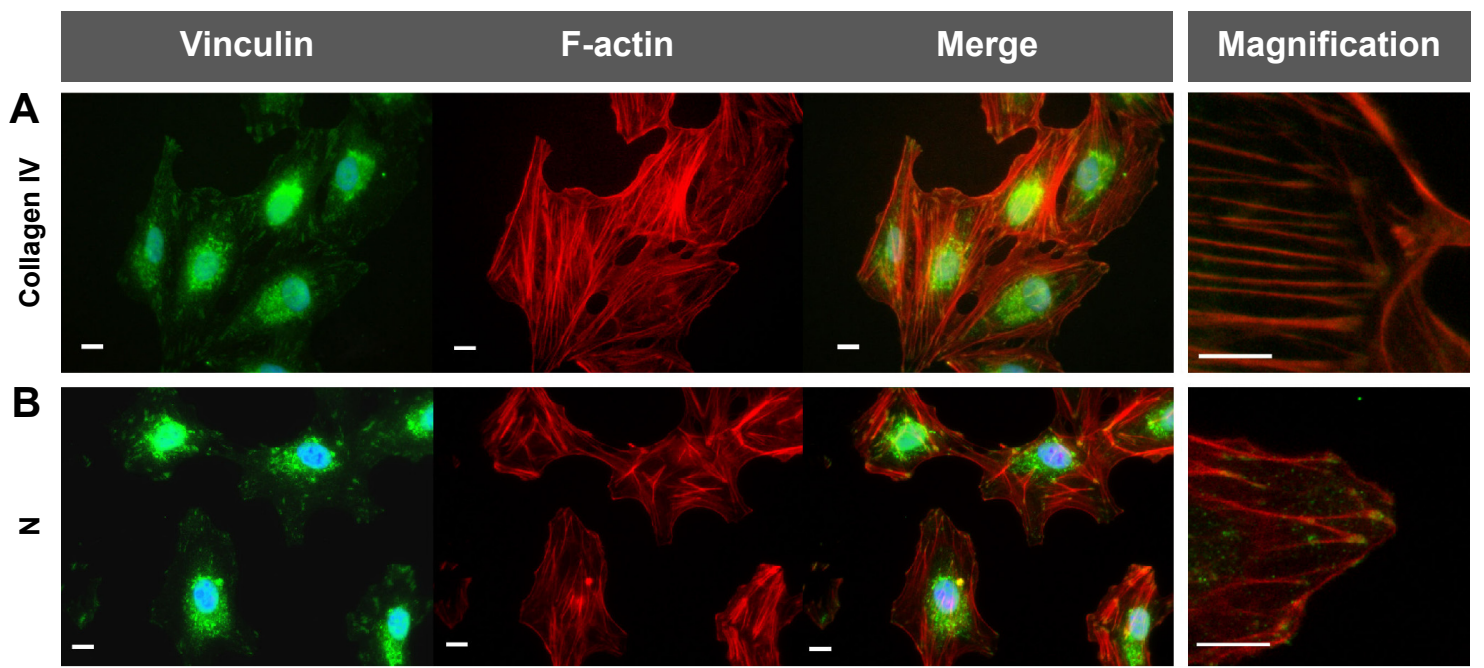

C
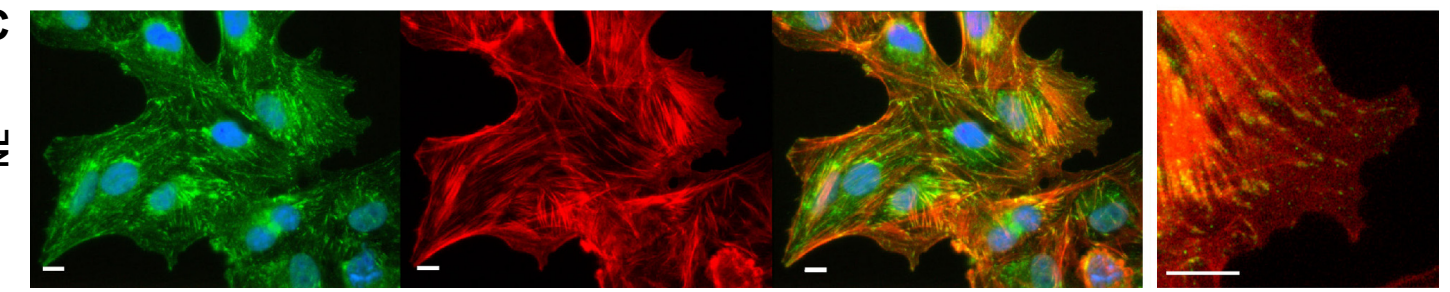

Figure 8 Podocyte focal adhesions and actin cytoskeleton.

Notes: Representative images of the human podocyte cell line after 2 days of culture. Though cells are not yet arborized, vinculin (left panels) positivity is higher in cells grown on (A) collagen-coated plastic and on (C) NE surface than in cells adherent to the (B) N surface. Phalloidin-rhodamine (middle panels) confirms the preferential organization of the actin cytoskeleton in stress fibers in (A) collagen-coated and (C) NE surface, whereas peripheral actin prevails in cells grown on (B) $\mathrm{N}$ material. Merging (right panels), particularly at higher magnification, shows that vinculin co-localizes with the tip of actin filaments in $(\mathbf{A})$ and $(\mathbf{C})$. Scale bars $=10 \mu \mathrm{m}$, merge magnification $\times 3$.

A

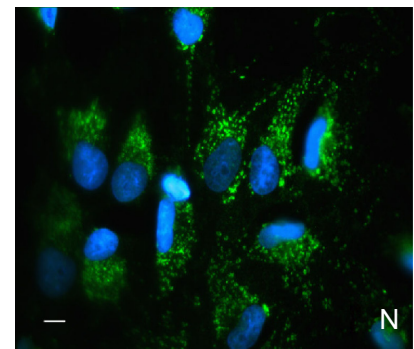

C
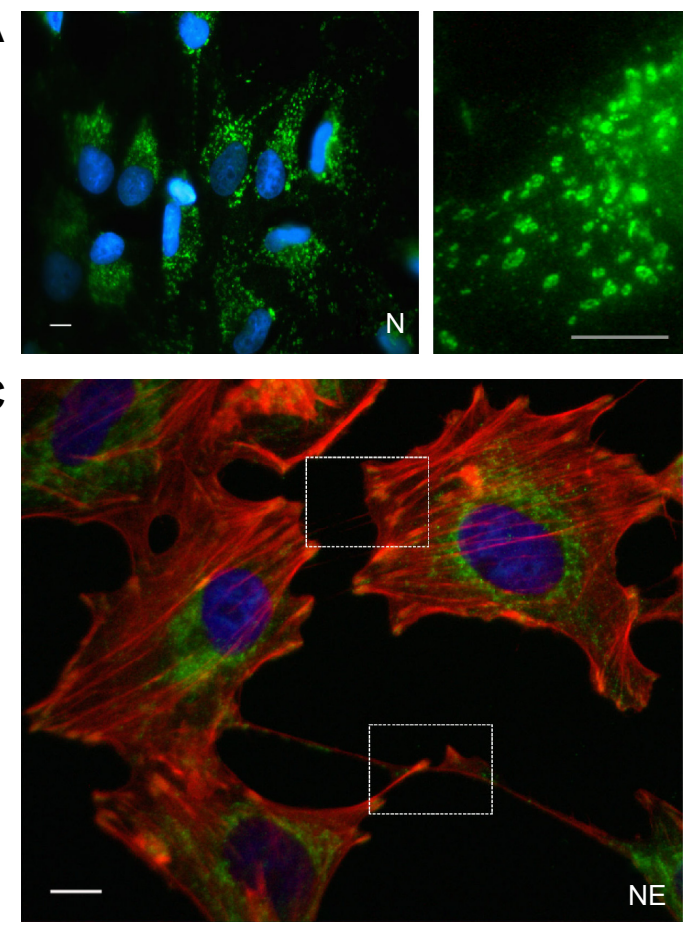

B

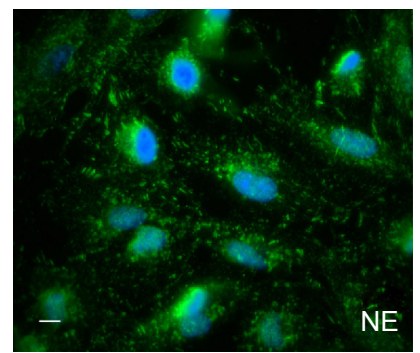

D
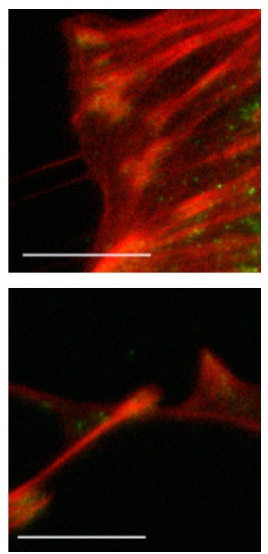

Figure 9 Podocyte focal adhesions and actin cytoskeleton.

Notes: After 5 days of culture, the human podocyte cell line grown on (A) $\mathrm{N}$ surface shows cytoplasmic vinculin with a rounded appearance, typical of the inactive molecule. In contrast, a punctated pattern is present in cells seeded on the (B) NE material. (C) Vinculin puncta of cells grown on NE surface co-localize with actin tips, as better observed at (D) higher magnification $(\times 3)$. Scale bars $=10 \mu \mathrm{m}$. The second panels of panels $(\mathbf{A})$ and $(\mathbf{B})$ represent higher magnification $(\times 4)$. 

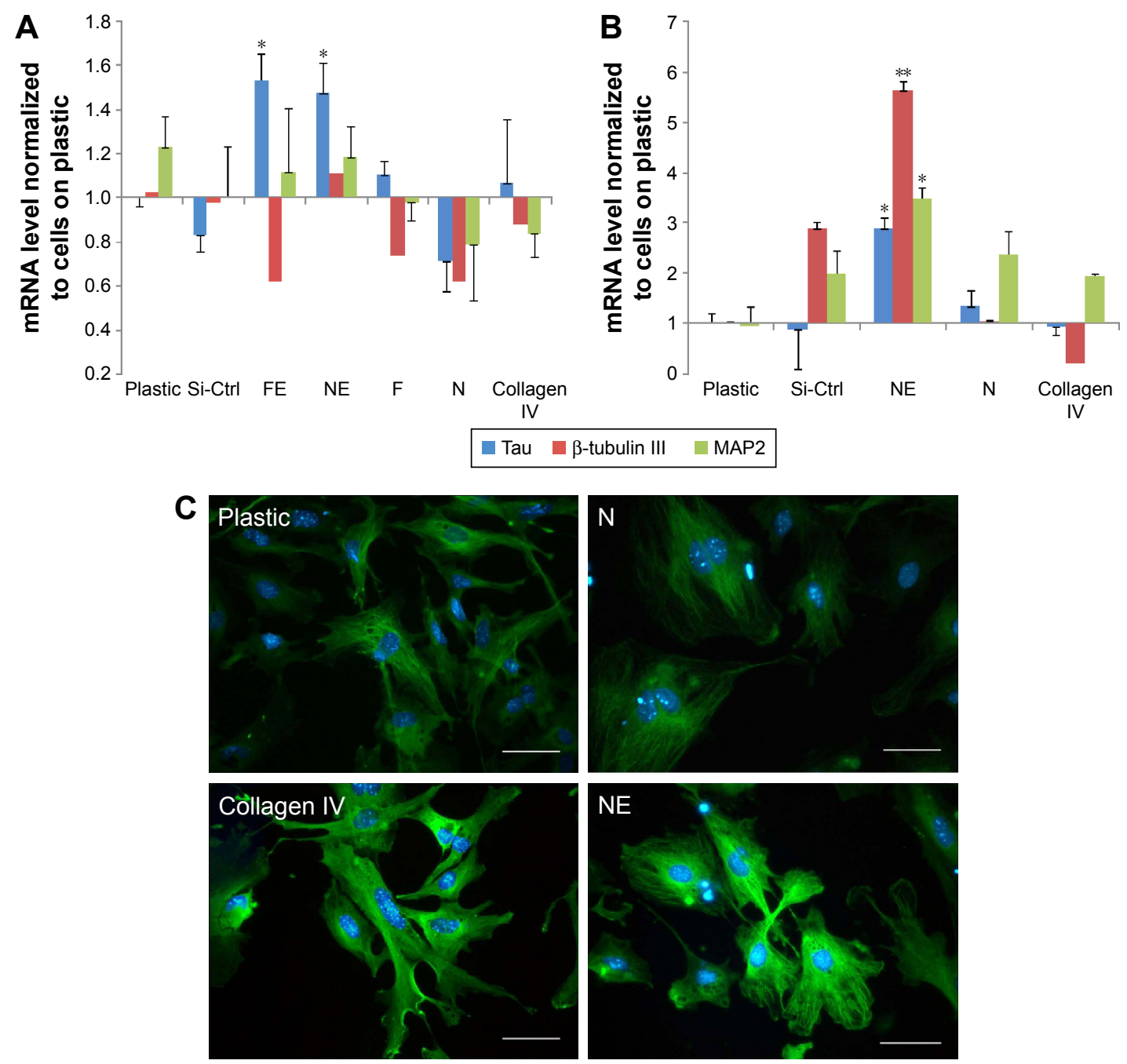

Figure 10 Podocyte expression changes.

Notes: At 5 days of culture, the (A) human podocyte cell line shows a statistically significant increase of Tau (blue bars) in cells seeded on porous surfaces. (B) Mouse primary podocytes display a significant increase of Tau (blue bars), $\beta$-tubulin III (red bars), and MAP2 (green bars) when grown on the NE surface. $* P<0.0 \mathrm{I}$ and $* * P<0.00 \mathrm{I}$ compared to plastic. (C) Immunostaining shows that mouse primary podocytes display increased and more ordered positivity (along the longitudinal axis of the cell) for $\beta$-tubulin III, when grown on collagen-coated plastic (second row, left panel) or on the NE surface (second row, right panel) than cells grown on uncoated plastic (first row, left panel) or on the $\mathrm{N}$ surface (first row, right panel). Scale bars $=50 \mu \mathrm{m}$.

as MAP2 and Tau ${ }^{12,37}$ and synaptic molecules such as synaptophysin..$^{38}$ Increased MAP2 and Tau (Figure 10A) as well as $\beta$-tubulin III (Figure 10C) were observed at day 5 of culture onto both porous surfaces NE and FE. No differences were found in synaptophysin expression.

\section{Discussion}

Cells interact with the ECM in a complex manner that comprises molecular as well as geometrical cues. ${ }^{39-41}$ Cell-matrix molecular interactions have been revealed by numerous in vitro and in vivo experimental studies, but the relationship between specific cell types and the geometry of the surface to which they attach remains mostly to be analyzed. Nanotechnologies are useful for these studies because of the unique opportunity to utilize and modify diverse biocompatible materials and build substrates which differ only by topology. Basement membranes are not the same in all tissues but differ in the geometry of 5-200 nm size pits, pores, protrusions, and fibers so that nanostructured biomaterials can mimic the spatial organization and separation distances which are characteristic of each specific basement membrane. ${ }^{42}$

In the present study, rough and porous surfaces in which pillars and grooves are separated by a distance $<58 \mathrm{~nm}$, which corresponds to the maximum distance required for correct establishment of focal adhesions, ${ }^{25,43}$ were obtained from silicon and compared not only to flat silicon but also to plastic surfaces which are routinely utilized for traditional 2D cell cultures. 
Although flat silicon was in itself advantageous as compared to plastic in terms of biocompatibility, it was not sufficient to influence cell differentiation, supporting the concept that cells need more specific stimuli from their microenvironment. In addition, all nanopatterned surfaces were found to absorb more medium components than flat materials, suggesting a diverse biomolecular relationship with the contacting cells.

The SH-SH5Y neuronal cell line was utilized as a control because of its known sensitivity to environmental stimuli. ${ }^{44}$ Our experiments confirmed the ability to sense surface roughness and to respond with changes in adhesion, development, and function. ${ }^{6}$ In addition, our studies indicate that the density of pillars is relevant to acquire enhanced differentiation of the cell line because the $\mathrm{N}$ material, characterized by smaller and nearer pillars, resulted to be the optimal environment to favor cell differentiation. Therefore, this specific geometry mimics the environment required for dopaminergic neuronal cells, which show similar changes as those obtained with RA routinely utilized to obtain cell differentiation in 2D cell cultures. ${ }^{28,30,31,45,46}$

Perhaps not surprisingly, a completely different geometric nanoporous surface nurtured primary rodent and human podocytes, on which arborized cell processes were formed similarly to those traditionally obtained by collagen coating. In this sense, podocytes, despite the presence of numerous ramifications, display a similar behavior to that of other epithelial cell types whose attachment and spreading seem to be discouraged by rough surfaces ${ }^{47,48}$ and facilitated instead by nanoporous materials. ${ }^{49}$ This behavior was not unexpected as it indirectly confirms what is known about the geometry of the GBM surface obtained by SEM studies performed after freeze-fracture procedures optimized to get a view of the GBM itself. From these analyses, the GBM appears indeed porous, which is required for the primary filtering function of the glomerular capillary. ${ }^{26,50-54}$

During embryological development, podocyte precursors display a cuboidal shape and subsequently develop primary major processes and secondary foot processes, which intertwine among themselves and completely enwrap the GBM. Adhesion of podocyte processes to the GBM involves a focal integrin-mediated adhesion structure described as a "cellular sensing machinery" formed by vinculin, talin, and paxillin, which direct focal adhesion assembly by linking actin to transmembrane integrins. ${ }^{2}$ Similarly, in vitro immature podocytes have a cobblestone shape, and maturation proceeds after firm cellular adhesion with the formation of ramifications. As confirmed by our results, these events are accompanied by profound remodeling of the actin cytoskeleton, ${ }^{55}$ with formation of stress fibers. As regard adhesion, both rough and porous materials were initially able to induce immature vinculin expression, as shown by a homogeneous distribution of the molecule in the cytoplasm. However, only porous surfaces allowed the formation of mature large and stable punctate focal contacts which appeared after 5 days of incubation and co-localized with actin filaments. In contrast, at the same time point, only inactive vinculin was present in cells seeded on rough nanosurfaces, demonstrating the absence of mature focal adhesions. ${ }^{56}$ These findings also suggest that before structuring permanent adhesions, podocytes test the microenvironment forming labile and soft interactions, a behavior which is likely relevant to find the exact orientation of the cell body and of cell ramifications on the preferred surface and is followed by the establishment of mature and stable contacts.

Several studies have demonstrated a series of analogies between podocytes and neuronal cells, particularly concerning the organization of the cytoskeleton and the formation of cell ramifications. ${ }^{10-12,57}$ Our experiments confirm these results, showing that differentiation of both cell types starts from cytoskeletal changes expressed, for instance, as an increase in MAP2 expression. MAP2 belongs to the class of microtubule-associated proteins, an abundant group of cytoskeleton components predominantly expressed in neurons. In these cells, microtubules are essential for formation and maintenance of neurites, and specifically, MAP2 contributes to microtubule stabilization by tubulin polymerization in association with Tau. ${ }^{11}$ Additional evidence also demonstrated the role of MAPs in bridging microtubules and actin microfilaments in several cell types. ${ }^{58} \mathrm{~A}$ significant upregulation of MAP2 expression has been described during neuronal differentiation of human mesenchymal stem cells in the presence of nanostructured surfaces with or without RA as compared to flat surfaces. ${ }^{5}$ In our hands, the cytoskeletal changes may represent a prerequisite for the subsequent increased expression of dopaminergic neuronal markers which confirm the complete differentiation. ${ }^{28}$

Similar to neuronal cells, mature podocytes show major processes which are microtubule-based cellular extensions interwoven with intermediate filaments and secondary foot processes containing a microfilament-based contractile apparatus composed of actin, myosin-II, $\alpha$-actinin, talin, and vinculin. ${ }^{10}$ Neuronal MAPs have been shown to promote microtubules assembly in podocytes; ${ }^{10,11}$ in particular, MAP2 and Tau were both demonstrated in podocytes ${ }^{10-12}$ suggesting a role in bridging microtubules and actin 

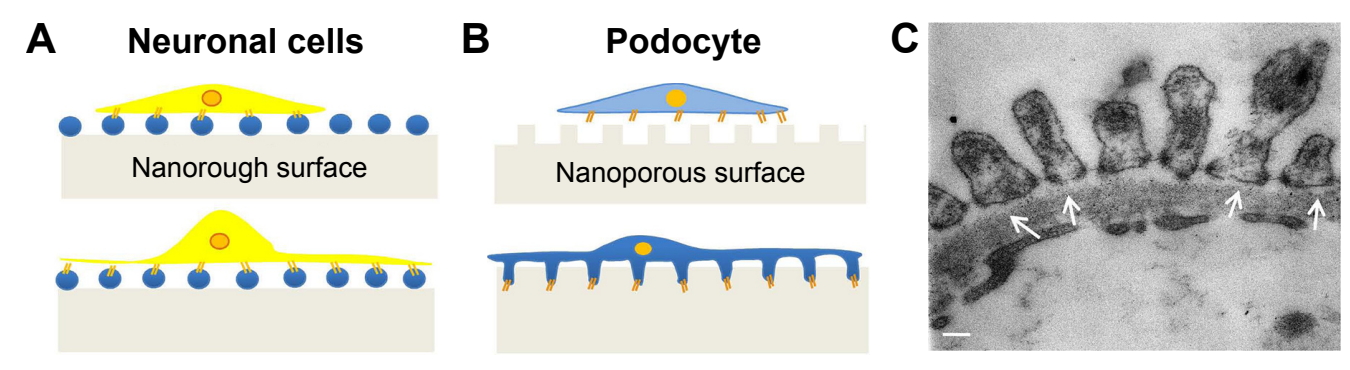

Figure II Geometry recognition differences between a neuronal cell line and podocytes.

Notes: (A) The neuronal cell line has a preference for artificial surfaces provided with pillars which promote appropriate cellular adhesion and differentiation. On the contrary, (B) podocytes preferentially recognize grooves and pores on cross section, suggesting that this type of surface better resembles the three-dimensional surface of the GBM in vivo, represented in a (C) transmission electron microscopy image of a normal rat glomerulus, with arrows indicating the adhesion areas between the foot processes and the GBM. Scale bar $=100 \mathrm{~nm}$.

Abbreviation: GBM, glomerular basement membrane.

microfilaments, which are essential to cellular maturation. The role of microtubules in podocyte development is confirmed by our results showing increased expression of microtubule-related molecules including MAP2, Tau, and the neuronal tubulin isoform $\beta$-tubulin III, which are particularly induced by the NE surface, characterized by closer and more regularly spaced grooves than the FE material. Immunofluorescence analysis of $\beta$-tubulin III not only showed its increased expression but also demonstrated the preferential longitudinal orientation of the molecule when cells were grown on the NE surface.

As summarized in Figure 11, the present study shows that two different types of ramified cells - neuronal cells and podocytes - are able to recognize and firmly attach to substrates according to the precise geometry which better reproduces the in vivo microenvironment. Culture studies specifically associating the preferred molecular and topographical cues for any cell types seem to be the best way to improve validity and reproducibility of in vitro findings.

The hallmark of numerous proteinuric renal diseases is podocyte injury characterized by foot process effacement, dedifferentiation, and detachment from the basement membrane with migration or loss. The results of this study seem to suggest that extracellular topographic cues play a critical role in initiation and maintenance of cell adhesion and phenotype fate. Importantly, the control of this cell behavior can be achieved by modifying the pattern of the topographic characteristics. Thus, we propose a simple, robust, and accessible biomimetic nanostructured platform with the potential to model in vitro podocyte cell biology and pathology, which may be applicable also to podocyte-endothelial coculture systems,${ }^{59}$ virtually recapitulating the glomerular filtration barrier. Critically, this may find utility in the investigation and further understanding of molecular pathways at the heart of podocyte well-being and injury.

\section{Summary and conclusion}

In this study, we present a series of experiments conducted on podocytes and neuronal cells, two cell types that, despite a number of commonalities, are very different in their behavior and function and are connected, in vivo, to different types of ECM. Our results seem to show that also in vitro, these cells behave differently in that they recognize and grow on specific 3D substrates. The importance of geometrical cues, and a better reproduction of in vivo characteristics, is highlighted by our data and can offer a starting point for future in vitro studies.

\section{Acknowledgments}

This work was supported by "Fondazione la Nuova Speranza ONLUS - Lotta alla Glomerulosclerosi Focale”, Rho, Italy. Funding was also received from "Fondazione Benefica Kathleen Foreman Casali", Trieste, Italy. Dr Tonon is presently the recipient of a Telethon Foundation research contract.

\section{Disclosure}

The authors report no conflicts of interest in this work.

\section{References}

1. Mendes PM. Cellular nanotechnology: making biological interfaces smarter. Chem Soc Rev. 2013;42(24):9207-9218.

2. Lim JY, Dreiss AD, Zhou Z, et al. The regulation of integrin-mediated osteoblast focal adhesion and focal adhesion kinase expression by nanoscale topography. Biomaterials. 2007;28(10):1787-1797.

3. Migliorini E, Grenci G, Ban J, et al. Acceleration of neuronal precursors differentiation induced by substrate nanotopography. Biotechnol Bioeng. 2011;108(11):2736-2746.

4. Fabbro A, Bosi S, Ballerini L, Prato M. Carbon nanotubes: artificial nanomaterials to engineer single neurons and neuronal networks. ACS Chem Neurosci. 2012;3(8):611-618.

5. Yim EK, Pang SW, Leong KW. Synthetic nanostructures inducing differentiation of human mesenchymal stem cells into neuronal lineage. Exp Cell Res. 2007;313(9):1820-1829. 
6. Brunetti V, Maiorano G, Rizzello L, et al. Neurons sense nanoscale roughness with nanometer sensitivity. Proc Natl Acad Sci US A. 2010; 107(14):6264-6269.

7. Kriz W, Shirato I, Nagata M, LeHir M, Lemley KV. The podocyte's response to stress: the enigma of foot process effacement. Am J Phys Renal Physiol. 2013;304(4):F333-F347.

8. Lennon R, Randles MJ, Humphries MJ. The importance of podocyte adhesion for a healthy glomerulus. Front Endocrinol (Lausanne). 2014;5:160.

9. Kriz W, Lemley KV. A potential role for mechanical forces in the detachment of podocytes and the progression of CKD. J Am Soc Nephrol. 2015;26(2):258-269.

10. Kobayashi N, Gao SY, Chen J, et al. Process formation of the renal glomerular podocyte: is there common molecular machinery for processes of podocytes and neurons? Anat Sci Int. 2004;79(1):1-10.

11. Kobayashi N. Mechanism of the process formation; podocytes vs. neurons. Microsc Res Tech. 2002;57(4):217-223.

12. Smoyer WE, Mundel P. Regulation of podocyte structure during the development of nephrotic syndrome. J Mol Med. 1998;76(3-4): $172-183$.

13. Suleiman $\mathrm{H}$, Zhang L, Roth R, et al. Nanoscale protein architecture of the kidney glomerular basement membrane. Elife. 2013;2:e01149.

14. Bakeine GJ, Bertolotti A, Latina M, et al. Surface properties and implantation site affect the capsular fibrotic overgrowth. J Biomed Mater Res A. 2007;83(4):965-969.

15. Bakeine GJ, Bertolotti A, Zennaro C, et al. Design and fabrication of large area nano-structured substrates for use in pancreatic beta-cell engineering. Microelectron Eng. 2009;86(4-6):1468-1472.

16. Timpl R. Macromolecular organization of basement membranes. Curr Opin Cell Biol. 1996;8(5):618-624

17. Rajnicek A, McCaig C. Guidance of CNS growth cones by substratum grooves and ridges: effects of inhibitors of the cytoskeleton, calcium channels and signal transduction pathways. J Cell Sci. 1997;110(Pt 23): 2915-2924

18. Dowell-Mesfin NM, Abdul-Karim MA, Turner AM, et al. Topographically modified surfaces affect orientation and growth of hippocampal neurons. J Neural Eng. 2004;1(2):78-90.

19. Christopherson GT, Song H, Mao HQ. The influence of fiber diameter of electrospun substrates on neural stem cell differentiation and proliferation. Biomaterials. 2009;30(4):556-564.

20. Lee DA, Knight MM, Campbell JJ, Bader DL. Stem cell mechanobiology. J Cell Biochem. 2011;112(1):1-9.

21. Markert LD, Lovmand J, Foss M, et al. Identification of distinct topographical surface microstructures favoring either undifferentiated expansion or differentiation of murine embryonic stem cells. Stem Cells Dev. 2009;18(9):1331-1342.

22. Park J, Bauer S, von der Mark K, Schmuki P. Nanosize and vitality: TiO2 nanotube diameter directs cell fate. Nano Lett. 2007;7(6):1686-1691.

23. Meinel AJ, Kubow KE, Klotzsch E, et al. Optimization strategies for electrospun silk fibroin tissue engineering scaffolds. Biomaterials. 2009;30(17):3058-3067.

24. Wang G, Ao Q, Gong K, et al. The effect of topology of chitosan biomaterials on the differentiation and proliferation of neural stem cells. Acta Biomater. 2010;6(9):3630-3639.

25. Jeon H, Simon CG Jr, Kim G. A mini-review: cell response to microscale, nanoscale, and hierarchical patterning of surface structure. J Biomed Mater Res B Appl Biomater. 2014;102(7):1580-1594.

26. Hironaka K, Makino H, Yamasaki Y, Ota Z. Renal basement membranes by ultrahigh resolution scanning electron microscopy. Kidney Int. 1993;43(2):334-345.

27. Rosenfeld G, Morgenstern K, Esser M, Comsa G. Dynamics and stability of nanostructures on metal surfaces. Appl Phys A Mater. 1999;69(5): 489-496.

28. Constantinescu R, Constantinescu AT, Reichmann H, Janetzky B. Neuronal differentiation and long-term culture of the human neuroblastoma line SH-SY5Y. J Neural Transm Suppl. 2007;(72):17-28.
29. Doublier S, Musante L, Lupia E, et al. Direct effect of plasma permeability factors from patients with idiopatic FSGS on nephrin and podocin expression in human podocytes. Int J Mol Med. 2005;16(1):49-58.

30. Edsjo A, Holmquist L, Pahlman S. Neuroblastoma as an experimental model for neuronal differentiation and hypoxia-induced tumor cell dedifferentiation. Semin Cancer Biol. 2007;17(3):248-256.

31. Vesanen M, Salminen M, Wessman M, Lankinen H, Sistonen P, Vaheri A. Morphological differentiation of human SH-SY5Y neuroblastoma cells inhibits human immunodeficiency virus type 1 infection. J Gen Virol. 1994;75(Pt 1):201-206.

32. Werth D, Grassi G, Konjer N, et al. Proliferation of human primary vascular smooth muscle cells depends on serum response factor. Eur J Cell Biol. 2010;89(2-3):216-224.

33. Zennaro C, Rastaldi MP, Pascolo L, et al. Podocyte expression of membrane transporters involved in puromycin aminonucleoside-mediated injury. PLoS One. 2013;8(6):e66159.

34. Qi L, Li N, Huang R, et al. The effects of topographical patterns and sizes on neural stem cell behavior. PLoS One. 2013;8(3):e59022.

35. Korecka JA, van Kesteren RE, Blaas E, et al. Phenotypic characterization of retinoic acid differentiated SH-SY5Y cells by transcriptional profiling. PLoS One. 2013;8(5):e63862.

36. Lopes FM, Schroder R, da Frota ML Jr, et al. Comparison between proliferative and neuron-like SH-SY5Y cells as an in vitro model for Parkinson disease studies. Brain Res. 2010;1337:85-94.

37. Shankland SJ. The podocyte's response to injury: role in proteinuria and glomerulosclerosis. Kidney Int. 2006;69(12):2131-2147.

38. Rastaldi MP, Armelloni S, Berra S, et al. Glomerular podocytes contain neuron-like functional synaptic vesicles. FASEB J. 2006;20(7): 976-978.

39. Daley WP, Peters SB, Larsen M. Extracellular matrix dynamics in development and regenerative medicine. J Cell Sci. 2008;121(Pt 3): 255-264.

40. Shukla A, Slater JH, Culver JC, Dickinson ME, West JL. Biomimetic surface patterning promotes mesenchymal stem cell differentiation. ACS Appl Mater Interfaces. Epub 2015 Dec 17.

41. Dado D, Sagi M, Levenberg S, Zemel A. Mechanical control of stem cell differentiation. Regen Med. 2012;7(1):101-116.

42. Teixeira AI, Abrams GA, Bertics PJ, Murphy CJ, Nealey PF. Epithelial contact guidance on well-defined micro- and nanostructured substrates. J Cell Sci. 2003;116(Pt 10):1881-1892.

43. Cavalcanti-Adam EA, Aydin D, Hirschfeld-Warneken VC, Spatz JP. Cell adhesion and response to synthetic nanopatterned environments by steering receptor clustering and spatial location. HFSP J. 2008;2(5): 276-285.

44. Buttiglione M, Vitiello F, Sardella E, et al. Behaviour of SH-SY5Y neuroblastoma cell line grown in different media and on different chemically modified substrates. Biomaterials. 2007;28(19):2932-2945.

45. Linnala A, Lehto VP, Virtanen I. Neuronal differentiation in SH-SY5Y human neuroblastoma cells induces synthesis and secretion of tenascin and upregulation of alpha(v) integrin receptors. J Neurosci Res. 1997; 49(1):53-63.

46. Yu J, Gonzalez S, Martinez L, Diez-Pardo JA, Tovar JA. Effects of retinoic acid on the neural crest-controlled organs of fetal rats. Pediatr Surg Int. 2003;19(5):355-358.

47. Hamilton DW, Chehroudi B, Brunette DM. Comparative response of epithelial cells and osteoblasts to microfabricated tapered pit topographies in vitro and in vivo. Biomaterials. 2007;28(14):2281-2293.

48. Baharloo B, Textor M, Brunette DM. Substratum roughness alters the growth, area, and focal adhesions of epithelial cells, and their proximity to titanium surfaces. J Biomed Mater Res A. 2005;74(1):12-22.

49. Leong MF, Chian KS, Mhaisalkar PS, Ong WF, Ratner BD. Effect of electrospun poly(D,L-lactide) fibrous scaffold with nanoporous surface on attachment of porcine esophageal epithelial cells and protein adsorption. J Biomed Mater Res A. 2009;89(4):1040-1048.

50. Kubosawa H, Kondo Y. Quick-freeze, deep-etch studies of renal basement membranes. Microsc Res Tech. 1994;28(1):2-12. 
51. Shirato I, Tomino Y, Koide H, Sakai T. Fine structure of the glomerular basement membrane of the rat kidney visualized by high-resolution scanning electron microscopy. Cell Tissue Res. 1991;266(1):1-10.

52. Takami H, Naramoto A, Shigematsu H, Ohno S. Ultrastructure of glomerular basement membrane by quick-freeze and deep-etch methods. Kidney Int. 1991;39(4):659-664.

53. Reale E, Luciano L, Kuhn KW, Stolte H. Morphological and functional aspects of the glomerular basement membrane. Basic Appl Histochem. 1979;23 Suppl:5-11.

54. Wheeler EE, Herdson PB. Freeze fracturing and freeze drying of renal tissue for scanning electron microscopy. Am J Clin Pathol. 1973;60(2): 229-233.

55. Faul C, Asanuma K, Yanagida-Asanuma E, Kim K, Mundel P. Actin up: regulation of podocyte structure and function by components of the actin cytoskeleton. Trends Cell Biol. 2007;17(9):428-437.
56. Humphries JD, Wang P, Streuli C, Geiger B, Humphries MJ, Ballestrem C. Vinculin controls focal adhesion formation by direct interactions with talin and actin. $J$ Cell Biol. 2007;179(5):1043-1057.

57. Li M, Armelloni S, Zennaro C, et al. BDNF repairs podocyte damage by microRNA-mediated increase of actin polymerization. $J$ Pathol. 2015;235(5):731-744.

58. Sanchez C, Diaz-Nido J, Avila J. Phosphorylation of microtubuleassociated protein 2 (MAP2) and its relevance for the regulation of the neuronal cytoskeleton function. Prog Neurobiol. 2000;61(2): 133-168.

59. Li M, Corbelli A, Watanabe S, et al. Three-dimensional podocyteendothelial cell co-cultures: assembly, validation, and application to drug testing and intercellular signaling studies. Eur J Pharm Sci. 2016; $86: 1-12$.
International Journal of Nanomedicine

\section{Publish your work in this journal}

The International Journal of Nanomedicine is an international, peerreviewed journal focusing on the application of nanotechnology in diagnostics, therapeutics, and drug delivery systems throughout the biomedical field. This journal is indexed on PubMed Central, MedLine, CAS, SciSearch $®$, Current Contents $\AA /$ Clinical Medicine,

\section{Dovepress}

Journal Citation Reports/Science Edition, EMBase, Scopus and the Elsevier Bibliographic databases. The manuscript management system is completely online and includes a very quick and fair peer-review system, which is all easy to use. Visit http://www.dovepress.com/ testimonials.php to read real quotes from published authors.

Submit your manuscript here: http://www.dovepress.com/international-journal-of-nanomedicine-journal 